University of Louisville

ThinkIR: The University of Louisville's Institutional Repository

$5-2004$

\title{
A comparison of brief, single sessions of physical activity and relaxation/meditation on affective responses of female undergraduates.
}

Paul Gregory Salmon 1948-

University of Louisville

Follow this and additional works at: https://ir.library.louisville.edu/etd

\section{Recommended Citation}

Salmon, Paul Gregory 1948-, "A comparison of brief, single sessions of physical activity and relaxation/ meditation on affective responses of female undergraduates." (2004). Electronic Theses and Dissertations. Paper 1254.

https://doi.org/10.18297/etd/1254

This Master's Thesis is brought to you for free and open access by ThinkIR: The University of Louisville's Institutional Repository. It has been accepted for inclusion in Electronic Theses and Dissertations by an authorized administrator of ThinkIR: The University of Louisville's Institutional Repository. This title appears here courtesy of the author, who has retained all other copyrights. For more information, please contact thinkir@louisville.edu. 


\title{
A COMPARISON OF BRIEF, SINGLE SESSIONS OF PHYSICAL ACTIVITY AND RELAXATION/MEDITATION ON AFFECTIVE RESPONSES OF FEMALE UNDERGRADUATES
}

\author{
by
}

Paul G. Salmon

B.A., University of Notre Dame, 1971

M.A., DePaul University, 1974

Ph.D., DePaul University, 1976

\begin{abstract}
A Thesis Submitted to the Faculty of the Graduate School of the University of Louisville in Partial Fulfillment of the Requirements for the Degree of
\end{abstract}

Master of Science

Department of Exercise Physiology

University of Louisville

Louisville, Kentucky

May 2004 
A COMPARISON OF BRIEF, SINGLE-SESSIONS OF PHYSICAL ACTIVITY AND

RELAXATION/MEDITATION ON AFFECTIVE RESPONSES OF FEMALE

UNDERGRADUATES

by

Paul G. Salmon

B.A. University of Notre Dame, 1971

M.A., DePaul University, 1974

Ph.D., DePaul University, 1976

A Thesis Approved on

$\underline{1 / 22 / 04}$

by the following Thesis Committee:

Thesis Director 


\section{ACKNOWLEDGEMENTS}

I would like to thank my Thesis director, Dr. Kent Adams, for the generous gift of his support, enthusiasm, and knowledge throughout both this project and during my graduate studies in Exercise Physiology. I thank Dr. Bryant Stamford for stimulating and nurturing my interest in this field of study, and especially for the refreshing blend of wisdom, common sense, and psychological mindedness he brings to the field. I want to acknowledge the influence of Dr. Dermot Collins, both as a member of the Thesis Committee and as a role model, stemming from the personal and intellectual curiosity which led him to embark on graduate studies in this same field during his academic career at the University of Louisville. I also am grateful to Scott LaJoie, Ph.D., of Kleinert Hand Surgery Associates, and to Craig Ziegler of the University's Bioinformatics \& Biostatistics Department for reviewing the statistical analyses, as well to the exceptional student members of our research team who so generously and enthusiastically assisted in the many phases of this study. Finally, I thank my wife, Susan Matarese, for her constant support, patience, love, and cheerful outlook throughout this entire venture into a new academic dișcipline. 


\title{
ABSTRACT \\ A COMPARISON OF BRIEF, SINGLE-SESSIONS OF PHYSICAL ACTIVITY AND RELAXATION/MEDITATION ON AFFECTIVE RESPONSES OF FEMALE UNDERGRADUATES
}

\author{
Paul G. Salmon
}

December 8, 2003

This study compared brief, single sessions of physical activity (PA, self-paced treadmill walking) and relaxation/meditation ( $\mathrm{R} / \mathrm{M}$, the 'Body Scan') on positive and negative affect and anxiety measures in female undergraduates. Both were predicted to reduce negative and enhance positive affect. Differential effects of PA and R/M were predicted for participants with predominantly cognitive or somatic anxiety symptoms. Forty-six undergraduates were randomized to $\mathrm{PA}$ or $\mathrm{R} / \mathrm{M}$ interventions. Changes in positive and negative affect (Positive and Negative Affect Scale, PANAS) and anxiety (Spielberger State / Trait Anxiety Inventory) were assessed using multivariate, repeatedmeasures statistics. Both PANAS Negative Affect \& STAI anxiety scores declined following PA, but PANAS positive affect also declined. Similarly, R/M significantly reduced STAI and PANAS Positive Affect scores, and (marginally) PANAS negative affect. Anxiety reduction was greatest following $\mathrm{R} / \mathrm{M}$ for participants with cognitive anxiety symptoms, but the complementary prediction concerning P/A and somatic symptoms was not supported. 


\section{TABLE OF CONTENTS}

PAGE

ACKNOWLEDGEMENTS

ABSTRACT iv

TABLE OF CONTENTS $\mathrm{v}$

LIST OF TABLES vi

LIST OF FIGURES vii

\section{CHAPTER}

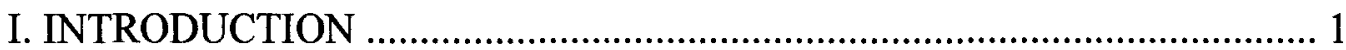

A. STUDY OVERVIEW ........................................................ 1

B. BACKGROUND ............................................................... 3

C. SUMMARY AND HYPOTHESES ........................................... 16

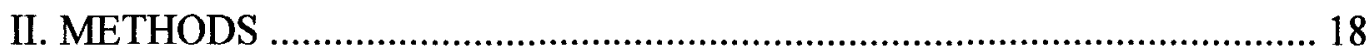

A. PARTICIPANTS .............................................................. 18

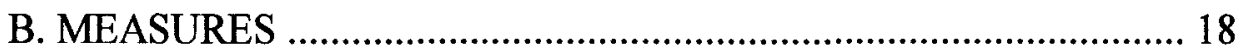

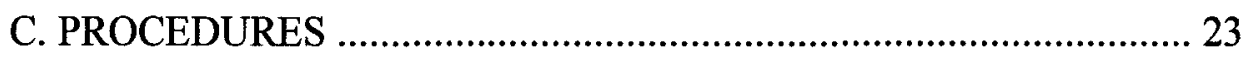

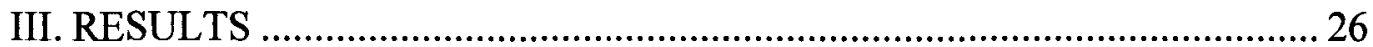

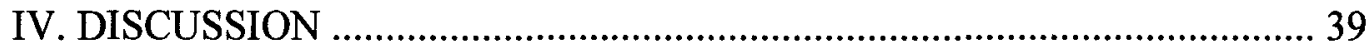

V. SUMMARY AND CONCLUSIONS .................................... 51

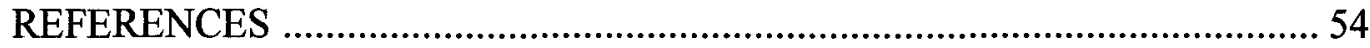

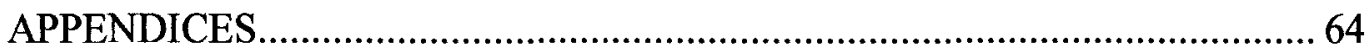

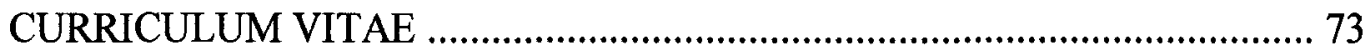




\section{LIST OF TABLES}

TABLE PAGE

1. Baseline Affect Rating Scores ….................................................... 27

2. Baseline Intercorrelations Among Principle Affect Measures ............. 28

3. Effects of Randomization: Baseline Group Means by Intervention ..... 30

4. Mean Differences, Pre- to Post-Intervention for PANAS and Spielberger Scales 31 


\section{LIST OF FIGURES}

FIGURE

1. Mean Brief STAI-S Scale Scores by Intervention and Measurement Period

2. Mean HR Values by Intervention for 8 Five-Minute Measurement Periods

3. Scatter Plot: Standardized CSAQ Difference Scores by Pre- to PostIntervention STAI/State Scores for R/M

4. Scatter Plot: Standardized CASQ Differences Scores by Pre- to PostIntervention STAI/State Scores for P/A 38 


\section{INTRODUCTION}

\section{A. Study Overview}

This study evaluated the affect-altering effects of single session, 22-minute interventions of either low intensity physical activity (PA, assessed via self-paced treadmill walking) or relaxation / meditation (R/M, 'Body Scan') in undergraduate college students. It is part of a larger project studying the selection and use of self-regulation strategies such as PA and R/M in reducing stress and promoting a sense of psychological well-being in the face of stressful illnesses such as cancer. The next stage in this process is to replicate the present study with female breast cancer survivors.

Both PA and R/M are forms of behavioral self-regulation, which can be used to help manage stress and promote states of psychological well-being, an added potential benefit of PA being at least a modest cardiovascular conditioning effect. This study is based on previous research showing that even single bouts of PA are effective in reducing stress, irrespective of pronounced physiological training effects. Such psychological benefits are easily overlooked due to the widespread tendency to 'medicalize' PA and emphasize physical conditioning, as exemplified by use of such terms as 'exercise dosage' and 'exercise prescription'. This viewpoint is reinforced by successful implementation of PA-based programs in medical rehabilitation setting, high-performance athletic training programs, and prescription-based PA as preventive measure to reduce risk of chronic health problems including heart disease, obesity, and diabetes. Implicit in this viewpoint 
is an assumption that the health benefits of PA depend on sustained and committed practice, which most people find challenging to sustain.

Easily overlooked in this medically and physiologically-driven view of PA are the potential psychological benefits: most people simply feel better after exercise -- more energetic, less stressed, more relaxed, etc. Interestingly, these perceptions may have less to do with either level of conditioning or physiological training effects than they do with cognitive / psychological interpretations of exercise, as recently summarized by Plante (Plante 1999) in a review of previous research. Self-efficacy, stress buffering, 'time out', enhanced social support, and even a meditative-like state were among the psychological effects attributed to PA.

This study investigated patterns of positive and negative (including 'state' anxiety) $\underline{\text { affect }}$-- short-term fluctuations in emotional states -- associated with 22-minute sessions of either low to moderate intensity PA (self-paced treadmill walking) or R/M. The latter involved single-session exposure to the 'Body Scan', an attention-focusing technique used in a stress reduction program based on mindfulness meditation (Kabat-Zinn 1990). Although the capabilities of both PA and M/R to reduce stress and anxiety have been independently verified, few studies have directly compared their anxiolytic effects.

It was hypothesized that, in terms of affective (i.e. 'feeling' - related) responses, relatively brief, single sessions of low-intensity exercise could achieve at least short-term effects comparable to those associated with a standardized $R / M$ technique in reducing present-moment tension / anxiety symptoms and promoting psychological well-being. A second hypothesis was that the tension-reducing effect of PA would be most evident in participants who, when anxious, experience predominantly somatic symptoms, whereas 
those with predominantly cognitive anxiety symptoms would show greatest pre- to postintervention changes in response to $\mathrm{R} / \mathrm{M}$.

\section{B. Background}

The following review focuses on studies documenting the anxiety-reducing effects of PA and R/M. Until recently, the psychological benefits of both PA and R/M have been evaluated primarily from the clinical perspective of anxiety reduction and stress management, focusing on symptoms reduction. More recent studies are beginning to also evaluate positive emotional benefits of these interventions as well. The following terminology is used to differentiate the emotional states referred to in this study:

- Affect: emotional states of relatively short duration (contrasted with 'mood', or one's long-term emotional tone).

- Anxiety: unpleasant affect typically associated with heightened sympathetic nervous system (SNS) activation (Stone 1997). 'State' anxiety refers to a scale developed by Spielberger (Spielberger 1979) to assess episodic, short-term anxiety, in contrasts to 'Trait' anxiety: A measure of chronic susceptibility to State anxiety. Together, these two scales comprise Spielberger's 'State-Trait Anxiety Inventory (STAI, Appendix A, p. $67 \& 68$ ). Reference is also made to the 'Cognitive / Somatic Anxiety Questionnaire (CSAQ, Appendix A, p. 65) (Schwartz 1978), which, conceptually independent of the STAI, distinguishes between mental ('cognitive') and physical ('somatic') anxiety symptoms.

- Negative Affect: One of two bipolar scales comprising the Positive and Negative Affect Scale (PANAS, Appendix A, p. 66) (Watson, Clark et al. 
1988). High scores are associated with unpleasant states such as anger and fear; low scores reflect a state of calm serenity.

- Positive Affect: The second of two bipolar scales from the PANAS. High scores denote a state of energy and enthusiasm, whereas low scores suggest lethargy and sadness.

Physical Activity and Anxiety Reduction: Since the 1970's, numerous studies have documented the apparent anxiolytic effect of exercise-based PA (for reviews see, for example (Bahrke and Morgan 1978) and (Morgan 1997)). Explanations of this effect have tended to focus either on cognitive or physiological factors. Concerning the former, one straightforward explanation, for which empirical support is available, (Breus and O'Connor 1998) is that exercise constitutes 'time out' from otherwise stressful circumstances, providing a diversionary period that is psychologically restorative. A second explanation is that exercise may reduce anxiety by promoting self-efficacy (perceived competence) (McAuley and Mihalko 1998). Alternatively, PA may help to reframe or 'decatastrophizing' anxiety symptoms, especially those associated with sympathetic nervous system (SNS) activation, as described in a case study by Salmon (Salmon 1992).

Physiological explanations for the anxiolytic effects of PA include increased body temperature and post-exercise, residual hypotension (Dishman 1992), both of which tend to be associated with relaxation states. Physical activity may also alter the activity of and interactions between neurotransmitters including serotonon, norepinephrine, and gamma-aminobutyric acid (GABA) (Buckworth and Dishman 2002) in an anxiolytic manner. The fact that PA is associated with elevated SNS activation may be related to 
secretion of endorphins, secretion, which have both analgesic and anxiolytic effects. (Thorens, Floras et al.1990). However, Dishman (Dishman 1992) suggested that the physiological benefits of exercise are primarily evident in highly trained athletes exercising at high intensity levels, not clinical patients with diagnosed anxiety disorders. Moreover, Buckworth and Dishman (Buckworth and Dishman 2002) noted that these studies have relied irtually exclusively on an anxiety scale (the Spielberger State-Trait Anxiety Inventory (STAI) (Spielberger 1983)) that tends to confound physiological activation with anxiety symptomatology.

Despite these limitations, meta-analyses conducted on large numbers of outcome studies generally support the hypothesis that PA has anxiolytic effects. The most widely cited of these (Petruzzello, Landers et al. 1991) concluded that aerobic PA / exercise has anxiolytic effects comparable in magnitude to relaxation sessions. A subsequent review by Long and van Stavel (Long and van Stavel 1995) confirmed Petruzzello's findings that the anxiolytic effect of PA appears to be robust, and is not simply a result of experimental artifact, such as the reduction in pre-performance apprehension (Petruzzello 1995). One consistent finding reported in these analyses is that exercise duration may be a more important variable than intensity in accounting for the anxiolytic effects of exercise. Petruzzello et al concluded that whereas a threshold of approximately twenty minutes duration appears to exist, there is no corresponding intensity threshold above or below which anxiolytic effects change markedly.

In an important series of recent papers, Ekkakakis (Ekkekakis, Hall et al. 1999; Ekkekakis and Petruzzello 1999; Ekkekakis and Petruzzello 2000) proposed reducing dependence on the STAI and 'anxiety' reduction and instead focus on the broader 
emotional construct of affect and how it may change prior to, during, and following exercise. In a series of studies reviewed below, he demonstrated that analyzing affective responses to PA yields a more comprehensive picture of the psychological experience of PA than one focused on 'anxiety reduction'. Collectively, studies reflecting both older and more contemporary views of anxiety and affect experience appear consistent in suggesting that PA alters emotional states in measurable and significant ways. The following studies represent a selective review of this literature.

Raglin and Morgan (Raglin and Morgan 1987) compared the effects of submaximal exercise and rest on measures of state anxiety and blood pressure. These authors treated resting quietly as an active intervention, with a potential to induce relaxation comparable to that of meditation and related techniques (i.e. Benson's Relaxation Response). Two groups of patients were tested in successive studies, the first consisting of 15 normotensive males averaging 34.2 years of age (Experiment 1), the second fifteen (apparently) male medication-controlled hypertensive patients (Experiment 2). Participants in Experiment 1 either rested quietly or exercised for 40 minutes on different days, with administration order determined randomly. In the exercise condition, both mode and intensity were selected by participants to enhance ecological validity (but at the cost of within-group homogeneity). The resting condition involved sitting in a quiet sound chamber with available (non-reactive) reading material, with instructions not to sleep.

In both conditions, blood pressure and state anxiety were assessed as follows: prior to, immediately following, and 20 minutes after the intervention; and subsequently after 1, 2, and 3 hours (note: measurement was terminated after 20 minutes in Experiment 
2). Results included a significant reduction in blood pressure immediately following either exercise or rest, but only in the exercise condition did the effect persist through the final measurement period ( 3 hours). State anxiety decreased significantly following exercise but not quiet rest, an effect that likewise persisted throughout the three-hour assessment period.

Similar results were obtained for the hypertensive sample, in that systolic blood pressure was significantly reduced immediately following exercise for both groups and persisted for 20 minutes following exercise but not rest. State anxiety scores decreased significantly in both conditions, immediately so following rest and 20 minutes after termination of exercise. It was concluded that both exercise and quiet rest reduced blood pressure and state anxiety ratings, but that these effects were prolonged only following exercise.

A straightforward study by Boutcher and Landers (Boutcher and Landers 1998) also reported activation following exercise, measured by State Anxiety (STAI-State anxiety scale), heart rate, and brain alpha activity. Thirty male college-age student runners and non-runners participated in either a vigorous run $(80-85 \% \mathrm{VO} 2 \mathrm{max})$ or quiet reading. Those who completed the exercise condition (two were excluded due to fatigue) reported lower anxiety, as measured by the STAI-State scale, whereas no reduction occurred in the reading condition.

As subsequent research would illustrate, the exercise intensity level was unnecessarily high to evoke an anxiolytic effect. Furthermore, the highly selective sample (college-age males capable of vigorous exercise) limits generalization to other healthy and clinical populations. Nevertheless, this study is interesting because it reflects so well 
several characteristics of early research in this area, namely: 1) that high intensity exercise was widely employed; 2) highly fit, male participants were the norm; 3 ) affective state was operationalized as 'anxiety', defined with reference to STAI-State scale scores; and 4) a reduction in anxiety was inferred based on changes in STAI scores, even though a significant proportion of the change was probably due to reduced autonomic nervous system activation that peaks and then declines following exercise and which is therefore not really the same as anxiety per se.

In a similar vein, Raglin and Wilson (Raglin and Wilson 1996) studied the effect of various intensities of aerobic exercise (cycle ergometry) on self-rated state anxiety. Fifteen male and female adults (mean age $=23.9 \mathrm{SD}=4.4$ ) completed 20 -minute cycle ergometry sessions at 40,60 , or $70 \%$ of their measured (VO2peak) oxygen uptake levels. Anxiety was assessed via the Spielberger STAI, and was significantly reduced sixty minutes following all exercise conditions, after increasing slightly within five minutes of exercise termination. The latter finding is common in studies employing the STAI, which does not discriminate between exercise and anxiety-based symptoms of sympathetic nervous system activation. Scores on the STAI-State scale are therefore likely to be elevated both during and immediately following physical exertion, diminishing thereafter. The finding that even light exercise intensities (i.e. 40\% VO2max) can significantly reduce anxiety has important implications for work with either clinical or non-clinical target populations whose conditioning levels are low.

A marked contrast to the work of Raglin and colleagues can be found in a series of studies more recently reported by Ekkakakis (Ekkekakis, Hall et al. 2000). This research represents a marked conceptual break with past studies, primarily because it 
employs a broad-based, conceptually contemporary model of affect rather than an operationally defined measure of anxiety. Furthermore, Ekkakakis' research demonstrated that measurable and reliable changes in affective state can be induced by brief, low intensity bouts of exercise well within the conditioning range of diverse healthy and clinical populations. In the first of four studies reported in this paper, 52 male and female undergraduate students in a health class completed a pre-test comprised of several measures of affect and were then randomly assigned to either a walking (RPE average 10.2, 'light' to 'fairly light') or reading (neutral content) control group. The walk, of 10 minutes duration, took place outdoors, whereas reading was done inside. Overall, participants in the walking group reported a shift toward more pleasant affective valence and higher 'energetic' activation, whereas those in the control condition reported no change. The second study incorporated an additional post-walk assessment to track the course of affect during recovery. One hundred thirty-five undergraduates (59 men, 76 women) either walked or read for ten minutes. Similar results were obtained, with the additional finding that the elevated state of pleasant, energetic affect persisted above baseline in the walking group for several minutes before declining, with no change noted either during or following the reading session.

The third and fourth studies in this series replicated the first two under more highly controlled laboratory conditions, with the duration of the exercise and reading sessions increased to 15 minutes. Similar results were obtained, with participants in the 'walking' condition reporting an increase in energetic activation and positive emotional valence in contrast to the 'reading' condition. These findings were corroborated further in 
the fourth study, which assessed individual differences in consistency by testing participants on two occasions, and which also included measures of EEG activity.

Of particular interest is that in none of these studies did state anxiety undergo a significant change, despite clear alterations in emotional valence and activation. The author concluded that using the former measure is unnecessarily restrictive in terms of obtaining a broadly representative view of emotional changes in the context of exercise.

Relaxation / Meditation Interventions: Clinical M/R procedures to reduce stress and anxiety have been developed and extensively validated in both psychiatric and medical applications. Among the best known of these are Jacobson's Progressive Muscle Relaxation ((Jacobson 1938) (Bernstein, Borkovec et al. 2000), Benson's Relaxation Response (Benson 1975); (Benson 1984), and meditation (Baime 1999), in particular a form termed 'mindfulness meditation' (Kabat-Zinn 1982); (Kabat-Zinn 1990). Common to virtually all $\mathrm{M} / \mathrm{R}$ techniques are a) a state of reduced physiological activation; b) relaxed but directed attention / awareness; and c) non-judgmental openness to ongoing experience (Lichstein 1988). Whereas physical relaxation alone is the goal of most relaxation techniques, more meditative forms emphasize in addition cognitive elements of directed attention and non-judgmental awareness which is believed to contribute to an overall state of relaxation.

Overall, two hypotheses of the anxiolytic effects of $\mathrm{M} / \mathrm{R}$ have predominated in this literature. The first explains anxiety reduction in terms of 'counterconditioning', in which anxiety symptoms are associated via exposure with relaxation states that are incompatible with and consequently inhibit the physiological activation characteristic of anxiety (see for example Wolpe (1958)). A second explanation, favored by advocates of 
meditative practices, is that the cognitive, physiological, and behavioral components of anxiety become de-associated from one another through a form of practice involving quiet sitting and learning to simply observe, rather than react to, thoughts and physiological states that would previously triggered anxious behavioral tendencies (Kabat-Zinn 1982).

Relaxation and meditation techniques have long been associated with reducing stress and anxiety (Lichstein 1988). Research on the anxiolytic effects of meditation has generally focused on one of two paradigms: the 'relaxation response' popularized by Benson (Benson 1975), which is based on Transcendental Meditation; and the tradition of 'mindfulness meditation' as interpreted by Kabat-Zinn and colleagues (Kabat-Zinn 1982); (Kabat-Zinn 1990). To date, a substantial body of research documenting the anxiety-reducing effects of the 'relaxation response' has accumulated in work with a wide variety of normal and clinical populations. Likewise, outcome studies suggesting that mindfulness meditation reduces stress associated with numerous medical conditions have been published, including research on chronic pain (Kabat-Zinn 1982; Kabat-Zinn 1985) (Kabat-Zinn, Lipworth et al. 1987); depression / anxiety (Kabat-Zinn, Massion et al. 1992) (Teasdale, Segal et al. 2000); psoraisis (Kabat-Zinn, Wheeler et al. 1998), fibromyalgia (Kaplan, Goldenberg et al. 1993); (Weissbecker, Salmon et al. 2002); and cancer (Massion, Teas et al. 1995); (Kabat-Zinn, Massion et al. 1998); (Speca, Carlson et al. 2000) (reviewed in Salmon et al (Salmon, Santorelli et al. 1998)).

The Mindfulness-based Stress Reduction program developed by Kabat-Zinn and colleagues (Kabat-Zinn 1990) makes use of three practices to foster states of relaxed, focused awareness: the Body Scan, yoga, and sitting meditation. The Body Scan was 
selected for this study owing to the fact that it can be implemented without extensive practice -- in fact, it is the first technique taught in the program. The body scan consists of a systematic, guided internal 'tour' of the body from head to feet. Conducted in a calm, relaxed atmosphere, the body scan emphasizes bringing moment-by-moment attention to discrete regions of the body with an attitude of acceptance and perceptual clarity. The body scan is structured through the use of a narration that begins with initial instruction in relaxed breathing, making this the focus of attention. Attention is then shifted to one foot (followed successively by the ankle, lower leg, knee, etc.) with instructions to simply pay attention to any sensations that may be present, without evaluation, judgment, or other cognitive processes.

The purpose of the body scan, as employed in the MBSR program is three-fold. First, it initiates the systematic development of moment-to-moment mindfulness by providing a broad field (internal sensations) for focused attention. It is the first skill taught in the program, and as such is relatively accessible to patients with no prior meditation experience. Second, the body scan is intended to promote simultaneous awareness and non-judgmental acceptance of one's body and corresponding physical sensations. Third, the technique provides practice in focusing attention, the key element of most meditation practices. By following the narration, practitioners learn to a) focus attention on specific regions of the body; b) systematically redirect attention to other regions; c) begin to notice how easily one's mind wanders from the intended focus of attention; and d) use this awareness to bring it back.

Comparing Anxiolytic Effects of PA and R/M: An especially interesting finding that emerged from Petruzzello's meta-analysis (Petruzzello, Landers et al. 1991) concerns the 
finding that both PA and M/R techniques were often found to have anxiolytic effects, even though the latter were included as comparison / control conditions, and despite the fact these interventions are at opposite ends of the physiological activation spectrum (Bahrke and Morgan 1978). However, few studies have directly compared the anxioloytic effects of M/R and PA, giving equal emphasis to both. Two early studies, by Bahrke and Morgan (Bahrke and Morgan 1978) and Schwartz, Davidson and Goleman (Schwartz 1978) directly addressed this issue.

In the first study, Bahrke and Morgan (Bahrke and Morgan 1978) evaluated the effects of sub-maximal exercise, meditation (Benson's Relaxation Response (Benson 1975)), and quiet sitting on anxiety levels assessed via the Spielberger STAI/State scale. Seventy-five adult males (mean age 51.9) who exercised regularly participated. They were randomly assigned ( 25 each) to exercise, meditation, and quiet rest (control) groups. Participants in the exercise group walked for 20 minutes on a treadmill at $70 \%$ of maximal heart rate (HRmax) previously determined by a Balke treadmill protocol (Balke and Ware 1959). Dependent measures included Borg ratings of perceived exertion (RPE; (Borg 1973), every five minutes, and heart rate (HR) was recorded every minute. Blood pressure was recorded ten minutes following the exercise session. Participants in the meditation group were given instructions in Benson's Relaxation Response (Benson 197 on audiotape, which they practiced for 20 minutes while seated in a recliner. Control group participants rested for 20 minutes and had the option of reading a non-reactive magazine. In both groups, resting metabolic rate, skin temperature, and HR were continuously monitored. 
Anxiety was assessed via the Spielberger STAI State and Trait scales at the time of recruitment into the study, prior to treatment randomization. State anxiety was subsequently assessed immediately upon conclusion of each treatment condition, and again ten minutes later. The principal finding was a significant reduction in self-reported State Anxiety in all three conditions, (including the quiet rest / control group). This effect occurred in participants assessed as both high and low in State Anxiety during baseline. In attempting to account for the apparent anxiolytic effect of the rest / control group, the authors suggested that all three conditions may have simply involved a diversional "time out" from anxiety-provoking circumstances. This reasoning implies that exercise accrues no unique physiological anxiolytic advantage in comparison to sedentary states, and that the effect of all three conditions on state anxiety could be accounted for in terms of a cognitive factor namely, the re-deployment of attention away from everyday concerns associated with anxiety.

In the second study, Schwartz, Davidson and Goleman (Schwartz 1978) assessed the impact of exercise and meditation on cognitive and somatic anxiety symptoms. Earlier, Davidson and Schwartz (Davidson and Schwartz 1976) proposed that the anxiolytic effects of diverse interventions such as relaxation, meditation, and exercise act on either cognitive or somatic symptom domains. Based on this reasoning, they hypothesized that anxiolytic effects are maximized when intervention and symptom domains are concordant. According to this view, an anxious, worry-prone individual with predominantly cognitive symptoms would find most relief from cognitively-oriented strategies. In contrast, someone troubled by physiological anxiety symptoms would respond most favorably to a somatically-based form of treatment. Thus, Davidson and 
Schwartz' model provides one way of addressing the paradoxical observation that exercise and relaxation / meditation - at opposite ends of an activation continuum - may both have anxiety-reducing properties, because each operates on a different facet of anxiety to reduce the overall level. The significance of the cognitive / somatic distinction for exercise research was subsequently reiterated by Sime (Sime 1984), and interest in the topic led to the development of several new assessment measures described and evaluated in a study by Steptoe (Steptoe and Kearsley 1990).

The study conducted by Schwartz, Davidson and Goleman (Schwartz 1978) directly tested Davidson and Schwartz' model. This study employed the Cognitive-Somatic Anxiety Questionnaire (CSAQ), the first psychometric instrument to formally assess these two symptom domains. The study consisted of a survey conducted on 77 participants, 44 who enrolled in an exercise class, and 33 meditation practitioners (predominantly Transcendental Meditation). The groups differed somewhat both in mean age (27.36, exercise group; 20.86 , meditation group) and gender (predominantly female, exercise group; equal, meditation group). Participants in each group completed the CSAQ as part of a larger study of self-regulation techniques. Meditation was considered to be representative of a 'cognitive' intervention, whereas exercise was identified as 'somatic'.

Consistent with Davidson and Schwartz' original hypothesis (Davidson and Schwartz 1976), it was predicted that whereas meditation would be associated with higher somatic and lower cognitive anxiety symptoms, exercise would produce the opposite pattern. Data were analyzed by comparing mean cognitive and somatic anxiety ratings for both groups, using a mixed (between / within) design analysis of variance. As predicted, meditation practice was associated with lower cognitive and marginally higher somatic 
anxiety symptoms, though the contrast was minimal. The opposite pattern was found for the exercising group, which however showed a markedly greater contrast. The groups did not differ statistically in overall CSAQ anxiety level. Among the authors' conclusions was that neither 'anxiety' nor 'relaxation' should be treated as global, highly differentiated constructs, despite their superficial dissimilarities. Rather, each is linked to marked individual differences in terms of how each is defined, practiced, and utilized to reduce distress symptoms.

C. Summary and Hypotheses: The purpose of the present study was to assess the impact of PA and R/M on affective states including, but not limited to anxiety. This study explored the extent to which stress-related symptoms of anxiety, a negative affective state, were affected by brief interventions (exercise and relaxation / meditation) representing two differing levels of physiological activation. Rather than relying exclusively on a unidimensional anxiety rating scale (the Spielberger STAI), the study also included the Positive and Negative Affect Scale (PANAS) to assess a broader range of affect states (Tellegen 1985). This study employed a between-subjects design in which participants were randomly assigned to either PA or R/M interventions, with time (pre- to post-intervention) as a within-subjects factor. The following hypotheses were evaluated:

Hypothesis I: A) It was predicted that both exercise and relaxation / meditation interventions would have a measurable and significant effect of decreasing in negative affective states, as assessed via the Spielberger State/Trait Anxiety Inventory (brief form) and PANAS Negative Affect scale. B) It was predicted that both interventions would have the effect of increasing feelings of well-being as well, as assessed via the PANAS Positive Affect scale. 
Hypothesis II: It was predicted that the anxiolytic effects of exercise and meditation would be greatest for individuals with concordant anxiety expression modalities, such that a) participants who experience anxiety predominantly via cognitive anxiety symptom will experience greatest anxiety reduction from relaxation / meditation, whereas b) participants who experience more somatic than cognitive anxiety symptoms will show greatest reduction in negative affect following exercise. 


\section{METHODS}

\section{A. Participants}

Forty-six female college students age eighteen or older were recruited for this study from a large Introductory Psychology lecture class. All received academic credit, having been given the option of participating in either research or abstracting research articles as extra-credit assignments. Participants were required to have exercise risk assessment scores within a 'Low' range, based on the Pre-Exercise Questionnaire, as well as Tension / Anxiety and Depression scales from the Profile of Mood States (McNair, Lorr et al. 1992) within 3 standard deviations of the mean. Both questionnaires are described below in the 'Measures' section.

These students represented a cross-section of female college undergraduates. Mean age was 19.89 (s.d. $=4.17$ ), and the majority were freshmen (mean years of school completed $=12.84$, s.d. $=.91)$. Just slightly more than half $(56 \%)$ reported exercising at least once per week at an intensity sufficient to significantly elevate HR. Average Body Mass Index (BMI) for this group was $23.23(\mathrm{~s} . \mathrm{d} .=5.35)$, within a range considered healthy (Howley and Franks 1997). Thirty-five of the participants were Caucasian, and 11 were African-American.

\section{B. Measures}

(Note: The present study is part of a larger research project which included several psychometric and psychophysiological measures not utilized here.) 
Prior to completing any assessment forms all participants were required to read and signed both the Informed Consent and Research Authorization forms, the latter mandated by the Health Insurance Privacy and Portability Act in research requiring disclosure of personal health information (See Appendix). Once these forms had been signed, the following two screening measures were administered.

\section{Profile of Mood States (POMS): The Profile of Mood States assesses} relatively enduring emotional states (i.e. moods) and has been widely used in studies of physical activity (Berger and Motl 2000) and clinical psychological research following its initial development and subsequent updates by McNair et al (McNair, Lorr et al. 1992). Of the six available scales on this inventory - Anxiety/Tension, Depression, Anger, Vigor, Fatigue, and Confusion - the Anxiety/Tension and Depression scales were immediately scored as a way of screening for excessively high ( 3 standard deviation units or greater) level of anxiety or depression. Subsequently, the remaining scales were scored for analyses unrelated to this study.

2. Pre-Exercise Questionnaire (PEQ): This assessment instrument, adopted for use in health and fitness facilities and based on American Heart Association risk guidelines, is used to assess suitability for initiating an exercise program. It screens for heart disease risk factors, musculo-skeletal / orthopedic problems, pregnancy, and common medical conditions. Heart disease risk level is stratified via a score derived from ten basic items that results in a classification of low, moderate, and high levels. In order to proceed with data collection, participants were required to have scores within the 'low' range. Participants whose scores on both the POMS and PEQ were within acceptable 
ranges then proceeded to the next phase of data collection, employing the following measures, listed in alphabetical order.

\section{Borg Scale: Rating of Perceived Exertion (RPE, 6-20 scale): This}

standardized self-rating scale to assess physical exertion for participants in the PA condition (Noble and Robertson 1996). It was developed and adapted for use in a variety of exercise and clinical settings by Borg (Borg 1998) in an effort to develop cognitive correlates of physiological activation. In this study, the 6-20 gradation RPE scale was used to provide participants with a context for establishing an appropriate walking pace.

\section{Cognitive-Somatic Anxiety Questionnaire (CSAQ, Appendix A): The} CSAQ was originally developed by Schwartz et al (Schwartz 1978) in the context of a study comparing the effects on relaxation states of meditation versus exercise described earlier. The CSAQ was developed in response to criticism of unidimensional assessment measures which do not differentiate somatic / physiological and cognitive anxiety symptoms. The inventory is comprised of 14 items appearing in randomized order and rated on a 5 point scale from 'not al all' to 'very much so'. Schwartz et al reported a correlation of .42 between the two components.

Results of subsequent validation studies provide mixed, but generally positive support for its use in research applications. An early study by Delmonte and Ryan (Delmonte and Ryan 1983) essentially confirmed the two-factor structure in 100 subjects recruited for a hospital-based study of meditative relaxation. Subsequently, Tamaren and Carney (Tamaren, Carney et al. 1985) conducted a valdiation study of the CSAQ in 22 university students enrolled in a self-management stress reduction course. They reported a low (.28) correlation between Cognitive and Somatic scales in keeping with the two 
factor concept; moderate correlation between the entire scale and an established anxiety measure; a positive correlations between somatic anxiety and skin conductance level; and finally a positive correlation between the cognitive scale and a measure of irrational beliefs. These findings are consistent with Schwartz et al's hypothesized two-component model of anxiety.

Heimberg, Gansler, et al (Heimberg, Gansler et al. 1987) evaluated the convergent and discriminant validity of the CSAQ in a clinical sample of 50 males and females seeking treatment for social phobia. They reported that, although the CSAQCognitive and CASQ-Somatic scales were fairly highly correlated (.58), the CSAQSomatic scale was most closely associated with a physiological measure (heart rate) whereas the CSAQ-Cognitive scale was related to worry and thought-listing measures.

DeGood and Tait (DeGood and Tait 1987) factor analyzed CSAQ data from 109 college students and identified a single somatic and multiple cognitive factors. Concerning construct validity, they reported significant correlations with several related anxiety measures, with somewhat more robust findings for males. A correlation of .62 was reported between cognitive and somatic scales in this study.

A clinical study offering less compelling support for the two-factor structure was conducted by Freedland and Carney (Freedland and Carney 1988). Subjects were 120 male and female adult psychiatric inpatients with at least one clinically significant anxiety symptoms at the time of admission. Analysis of this data yielded four, rather than two factors which accounted for a significant proportion (60\%) of the variance. A strong somatic factor was accompanied by three additional factors derived from CSAQCognitive scale items. The authors concluded that, although the CSAQ-Somatic scale 
appears relatively homogeneous, the CSAQ-Cognitive is less so. A subsequent factor analytic study by Steptoe and Kearsley (Steptoe and Kearsley 1990) using adult exercise and meditation practitioners confirmed the two-factor structure originally proposed by Schwartz et al. This study compared the CSAQ with two other, but less widely known two-factor measures of anxiety, the Lehrer-Woolfolk Anxiety symptom Questionnaire (LWASQ) (Lehrer and Woolfolk 1982) and the Worry-Emotionality Scale developed by Morris et al (Morris 1981).

3. Heart rate: Heart rate (HR) was monitored continuously prior to, during, and following both interventions on a minute-by-minute basis using a Polar HR monitor consisting of a transmitter unit embedded in a strap worn around the chest and a wrist receiver unit with a range of approximately 1 meter.

\section{Positive and Negative Affect Scale (PANAS, Appendix A): The PANAS} used to measure affective responses with both positive and negative valences (Watson, Clark et al. 1988). It is based on an earlier two-factor model of affect developed by Russell (Russell 1980), but differs somewhat in terms of how the factors are defined. Rather than referring to the two dimensions in terms of valence (pleasant vs unpleasant states) and arousal (low to high), Watson et al refer to one dimension as 'Positive Affect' and the second as 'Negative Affect'. 'Positive Affect' reflects a bipolar scale reflecting a range of affective states from highly positive and energetic at one end to sadness and lethargy at the other. 'Negative Affect' also describes a bipolar dimension, one that is anchored by negative feelings (anger, fear, nervousness) at one end and calmness / serenity at the other. The PANAS consists of 20 terms describing emotional states, each rated on a five-point scale ranging from 'Very slightly or not at all' to 'Extremely'. The 
context for ratings on PANAS items can be anywhere from the present moment ('you feel this way right now') to a global assessment ('you generally feel this way'). In the present study, PANAS ratings reflected present-moment feelings in order to determine whether or not pre- to post-intervention changes occur in affective states.

5. Spielberger State/Trait Anxiety Scale State form (STAI, Appendix A): For years, the STAI (Spielberger, Gorsuch et al. 1970), (Spielberger 1983) was perhaps the most widely used anxiety scale in both exercise and clinical research (Smith, Smoll et al. 1998); (Endler and Kocovski 2001), and its popularity has continued despite the fact that it is based on a unidimensional model of anxiety that has been superceded by multidimensional constructs. Both State and Trait forms of the STAI were administered, the latter at baseline only to assess participants enduring predisposition to anxiety. An abbreviated ( 8 item) version of the STAI-State anxiety scale (Rejeski, Hardy et al. 1991) was derived from the complete State Scale and used for ratings immediately following either intervention (See Appendix A, p. 67). The complete State scale was used to provide a more thorough assessment of overall changes in affect from baseline to the time period ten minutes post-intervention, in accordance with Ekkekakis (Ekkekakis, Hall et

al. 1999) recommendation that final assessment of 'state' anxiety should either be delayed until acute exercise-induced arousal has diminished.

\section{Procedure}

1. Recruitment and Screening: Participants were recruited via a posted sign-up sheet in the Department of Psychological and Brain Sciences. They were called the night before their scheduled lab session and instructed to wear comfortable clothing and shoes suitable for walking. They were not informed at this time which of the two interventions they would be assigned to; this determination was instead made at the conclusion of baseline 
data collection during the lab session. Upon reporting to the laboratory, all participants read and signed the Informed Consent form (Appendix B), as well as the Research Authorization form. They then received an initial screening assessment using the PreExercise Questionnaire (PEQ) and Profile of Mood States. The former was used to assess physical risk factors, the latter, employing the Tension and Depression scales was used to identify individuals with excessively high (three standard deviation or greater) levels of anxiety or depression. Referral information to both the Student Counseling Center and Psychological Services Center on the University of Louisville campus was potentially available to these individuals.

Following signing the Informed Consent and Research Authorization documents, each participant had a series of basic measures taken, including height and weight, by a female research assistant. The Polar heart rate monitor was also put in place at this time. Following this, each participant completed a set of baseline assessment measures including the PANAS, CSAQ, and Spielberger STAI/S. Following completion of baseline data collection, all participants sat quietly in a recliner for a ten minute period while heart rate (and other physiological measues not reported here) were monitored. Depending on whether the participant was randomized to the M/R or PA intervention, one of two procedures was followed next. Those in the exercise condition stepped onto the treadmill where they were given instructions for starting, stopping, walking, and controlling the speed. Those in the $\mathrm{M} / \mathrm{R}$ condition remained seated in the recliner. In either case, a timed, twenty-two minute session was then initiated during which HR was recorded each minute, along with other psychophysiological measures. 
At the conclusion of the exercise intervention, BP was recorded, and the brief StAI/State Scale was administered. Participants in the relaxation condition also completed the brief STAI/State Scale at the conclusion of this intervention. This was followed by a 10-minute session during which participants sat quietly while postintervention HR and other psychophysiological measures were monitored, at the conclusion of which final PANAS, and STAI/S questionnaires were re-administered. The total duration of this post-intervention period was 10 minutes, after which participants received a final debriefing prior to leaving the laboratory. On average, the experimental session encompassing both baseline and intervention data collection required between 80 and 90 minutes. 


\section{RESULTS}

This chapter is divided into two major sections: First, analyses of baseline measures to evaluate initial levels of key variables and assess the impact of randomization are reported. Second, analyses pertaining to each hypothesis are presented, beginning with a comparison of the impact of. PA and R/M on self-reported affect ratings. This is followed by a correlational analysis of CSAQ data to determine the extent to which cognitive or somatic anxiety symptoms interact with intervention mode (PA vs R/M) affect in affecting changes in affect ratings.

Pre-Intervention measures: Means and standard deviations for key variables (CSAQ, PANAS, Spielberger) are summarized in Table 1. All values are within 'normal' ranges, including Spielberger State and Trait Anxiety scores, compared to appropriate reference groups. To provide an overview concerning how these variables may be related, Table 2 summarizes the intercorrelations (Pearson $r$ ) among these measures. Of particular note is the lack of association between PANAS Positive and Negative Affect Scales ( $r=$ $-.046)$, suggesting the relative independence of these two factors.

Participants were randomly assigned to either the Exercise or Relaxation intervention. To minimize specific anticipatory effects, they were informed as to the intervention at the conclusion of the initial 10-minute baseline period, after they had completed filling out pre-intervention questionnaires. The effect of this randomization 
Table 1

Baseline Affect Rating Scores

\begin{tabular}{|c|c|c|c|c|c|}
\hline & $\mathrm{N}$ & Minimum & Maximum & Mean & S.D. \\
\hline PANAS Positive & 46 & 18 & $48 / 50$ & 30.41 & 6.18 \\
\hline PANAS Negative & 46 & 10 & $12 / 50$ & 12.37 & 2.24 \\
\hline STAI / State & 46 & 20 & $45 / 80$ & 32.24 & 7.17 \\
\hline STAI/ State (brief) & 46 & 08 & $16 / 32$ & 11.61 & 2.40 \\
\hline STAI/ Trait & 45 & 22 & $59 / 80$ & 35.49 & 7.64 \\
\hline CSAQ Cognitive & 46 & 7 & $35 / 35$ & 15.17 & 5.60 \\
\hline CSAQ Somatic & 46 & 10 & $28 / 35$ & 16.48 & 4.84 \\
\hline CSAQ total & 46 & 18 & $60 / 70$ & 31.65 & 8.54 \\
\hline
\end{tabular}


Table 2

Baseline Intercorrelations Among Principle Affect Measures

\begin{tabular}{|c|c|c|c|c|c|c|c|c|}
\hline & PANAS / P & PANAS/N & CSAQ/C & CSAQ/S & CSAQ/T & STAI/S & STAI /S br & STAI $/ \mathbf{T r}^{1}$ \\
\hline PANAS /P & 1.00 & -.046 & .188 & .249 & .264 & $-.463^{* *}$ & $-.326^{*}$ & $-.389^{* *}$ \\
\hline PANAS /N & & 1.00 & .200 & .127 & .203 & $.577^{* *}$ & $.688 * *$ & $.450^{* *}$ \\
\hline CSAQ /C & & & 1.00 & $.336^{*}$ & $.846^{* *}$ & .167 & .216 & $-.375^{*}$ \\
\hline CSAQ/S & & & & 1.00 & $.787^{* *}$ & .108 & .147 & -.016 \\
\hline $\mathrm{CSAQ} / \mathrm{T}$ & & & & & 1.00 & .171 & .224 & .237 \\
\hline STAI/S & & & & & & 1.00 & $.865^{* *}$ & $.653^{* *}$ \\
\hline STAI/S br & & & & & & & 1.00 & $.537^{* *}$ \\
\hline STAI / Tr' & & & & & & & & 1.00 \\
\hline
\end{tabular}

${ }^{* *}$ Correlation is significant at the 0.01 level (2-tailed)

* Correlation is significant at the 0.05 level (2-tailed)

${ }^{1} \mathrm{~N}=45 ;$ all other cells $\mathrm{N}=46$ 
procedure is addressed in Table 3, which summarizes results of a series of independentsample t-tests for the major affect outcome variables: total CSAQ cognitive symptoms; total CSAQ somatic symptoms; PANAS Positive and Negative affect; Spielberger State, brief State, and Trait scales; and HR. No significant differences were found between the two interventions for any of these dependent variables, suggesting that the groups were functionally equivalent at baseline.

Hypothesis 1 . Both exercise and relaxation were predicted to result in a significant increase in positive affect (PANAS/Positive scale), and decreased negative affect (PANAS/Negative and STAI/State (brief) scales). Thus, the analyses in this section focus on the effects of the two interventions (Exercise and Relaxation / Meditation) on three measures of affect: PANAS positive and negative scales, and the Spielberger STAI/S (brief form). Table 4 summarizes changes in mean scores for the PANAS/Positive, PANAS/Negative and Spielberger STAI/S (brief) across intervention conditions. As can be seen in this table, decreases were noted in all three affect measures - PANAS/Positive, PANAS/Negative, and Spielberger STAI/S (brief).

In order to assess the significance of these changes, two separate $2 \times 3$ doublymultivariate analyses of variance (Tabachnick and Fidell 2001) were carried out using the following variables: PANAS/Positive affect, PANAS/Negative affect, Spielberger STAI/S (brief) $\mathrm{x}$ two time intervals. This was a completely within-subjects design, with three affect scores measured at two times (pre- and post-intervention). For the exercise intervention $(n=26)$, the overall multivariate F statistic $(6.67)$ was significant $(p<.001)$. Given the significance of this result, subsequent univariate $F$ tests were conducted which revealed significant changes in PANAS/Positive $(F=4.66, p=.041)$, PANAS/Negative 
Table 3

Effects of Randomization: Baseline Group Means by Intervention. Independent Samples $\underline{T-T e s t s}$

\begin{tabular}{|c|c|c|c|c|c|c|c|c|}
\hline & $\mathbf{N}$ & Mean & S.D. & $\mathbf{T}$ & df & $\operatorname{sig} \cdot(2$ tail $)$ & Mean Difi \\
\hline \multirow[t]{2}{*}{ CSAQ/C } & Exercise & 20 & 14.50 & 4.82 & .931 & 44 & $\mathrm{p}=.357, \mathrm{~ns}$ & 1.55 \\
\hline & Relaxation & 26 & 16.05 & 6.48 & & & & \\
\hline \multirow[t]{2}{*}{ CSAQ/S } & Exercise & 20 & 16.38 & 4.81 & .148 & 44 & $p=.883, n s$ & .215 \\
\hline & Relaxation & 26 & 16.60 & 5.00 & & & & \\
\hline \multicolumn{2}{|c|}{ PANAS/P Exercise } & 20 & 29.55 & 6.39 & -.828 & 44 & $p=.412, n s$ & -1.53 \\
\hline & Relaxation & 26 & 31.08 & 5.95 & & & & \\
\hline \multicolumn{2}{|c|}{ PANAS/N Exercise } & 20 & 12.35 & 1.87 & .080 & 44 & $p=.927, n s$ & .05 \\
\hline & Relaxation & 26 & 12.40 & 2.70 & & & & \\
\hline \multirow[t]{2}{*}{ STAI/S } & Exercise & 20 & 31.19 & 7.45 & 1.132 & 44 & $p=.264, n s$ & 2.41 \\
\hline & Relaxation & 26 & 33.60 & 6.73 & & & & \\
\hline \multirow[t]{2}{*}{ STAI/Sbr } & Exercise & 20 & 11.12 & 2.37 & 1.619 & 44 & $p=.113, n s$ & 1.13 \\
\hline & Relaxation & 26 & 12.25 & 2.34 & & & & \\
\hline \multirow[t]{2}{*}{ STAI/T } & Exercise & 20 & 35.19 & 7.72 & .301 & 43 & $p=.765, n s$ & .70 \\
\hline & Relaxation & 26 & 35.89 & 7.73 & & & & \\
\hline \multirow[t]{2}{*}{ HR } & Exercise & 20 & 68.66 & 8.75 & -.756 & 44 & $p=.453, \mathrm{~ns}$ & -2.22 \\
\hline & Relaxation & 26 & 70.88 & 10.68 & & & & \\
\hline
\end{tabular}


Table 4

Mean Differences, Pre- to Post-Intervention for PANAS and Spielberger Scales

\begin{tabular}{|l|l|l|l|l|l|l|}
\hline & $\begin{array}{l}\text { Exercise } \\
\text { Mean }\end{array}$ & $\begin{array}{l}\text { Exercise } \\
\text { S.D. }\end{array}$ & $\begin{array}{l}\text { Exercise } \\
\mathrm{N}\end{array}$ & $\begin{array}{l}\text { Relaxation } \\
\text { Mean }\end{array}$ & $\begin{array}{l}\text { Relaxation } \\
\text { S.D. }\end{array}$ & $\begin{array}{l}\text { Relaxation } \\
\mathrm{N}\end{array}$ \\
\hline PANAS/P pre & 31.08 & 6.39 & 26 & 29.55 & 5.95 & 20 \\
\hline PANAS/P post & 28.08 & 5.91 & 26 & 23.75 & 7.09 & 20 \\
\hline PANAS/N pre & 12.35 & 1.87 & 26 & 12.40 & 2.70 & 20 \\
\hline PANAS/N post & 10.85 & 1.01 & 26 & 11.00 & 1.97 & 20 \\
\hline STAI/Sbr pre & 11.16 & 2.37 & 26 & 12.25 & 2.34 & 20 \\
\hline STAI/Sbr post & 9.42 & 1.70 & 26 & 9.20 & 2.34 & 20 \\
\hline
\end{tabular}


$(F=17.30, p<.001)$ and Spielberger STAI/brief $(F=8.40, p=.008)$. The overall pattern thus reflected a significant decrease in positive affect (PANAS/Positive), as well as predicted, and significant decreases in STAI/State (brief) symptoms and negative affect (PANAS/Negative).

With respect to the Relaxation intervention ( $n=20)$, similar, thought not identical results were obtained. An overall significant multivariate $F=17.00(p<.001)$ was obtained, followed by univariate tests to evaluate pre- to post-intervention change. Significant changes were found for PANAS/Positive affect $(F=18.82, p<.001)$ and STAI/S (brief) symptoms $(\mathrm{F}=27.85, \mathrm{p}<.001)$, but not for PANAS/Negative affect $(\mathrm{F}=$ $3.86, p=.064)$, though there is clearly a trend in the predicted direction.

The next analysis compared the effects of each intervention, using pre- to postchange scores for the same three variables. A multivariate analysis of variance (MANOVA) was run to assess possible differences between Exercise and Relaxation interventions for PANAS/Positive, PANAS/Negative, and Spielberger STAI/S (brief) change scores. The overall multivariate $F$ value of 1.98 was non-significant $(p=.132)$, indicating no significant difference in the overall magnitude of the two interventions' effect on these variables. Thus, it appears that exercise and relaxation attained comparable effects in terms of altering affect scores.

Finally, the pattern of negative affect change, as assessed by the Spielberger STAI/State (brief) inventory, was explored using a repeated measures MANOVA with intervention as the between-subjects variable. There were three measurement points: at baseline, immediately following either intervention, and again after a 10-minute postintervention measurement period. Results of this analysis revealed an overall significant 
multivariate $\mathrm{F}$ statistic for time $(13.84, \mathrm{p}<.001)$, as well as a significant interaction $(\mathrm{F}=$ $4.65, p=.015)$. A graphic representation of the main effect and interaction is presented in Figure 1. Inspection of this figure suggests that STAI/State (brief) scores declined markedly from baseline to immediate post-intervention following the Relaxation intervention, but more gradually following Exercise (which also started from a somewhat lower baseline level).

To corroborate the differential effect of each intervention on overall activation level, mean HR values were calculated for the following series of eight five-minute intervals: Baseline (two intervals), Intervention (four intervals), and post-intervention (two five-minute intervals). As expected, mean $\mathrm{HR}$ was significantly higher compared to baseline during the PA intervention. Heart rate remained consistently low throughout each interval in the $\mathrm{R} / \mathrm{M}$ condition (Figure 2). A repeated-measures multivariate analysis of variance revealed a significant main effect for time, consisting of eight 5-minute measurement periods $(\mathrm{F}=28.66, \mathrm{df}=7, \mathrm{p}<.001)$, as well as a significant interaction by treatment $(F=38.94, \mathrm{df}=7, \mathrm{p}<.001)$. These two effects are largely accounted for by the marked increase in HR during PA.

Hypothesis II: Exercise was predicted to have a greater impact, in terms of reducing negative affect as measured by pre- to post-intervention changes in STAI/State scale scores (using the complete, rather than brief form) for participants who experience anxiety via predominantly somatic symptoms, whereas relaxation/meditation was predicted to have a greater effect on negative affect for those who experience predominantly cognitive symptoms. This hypothesis was evaluated by computing a variable reflecting the difference between Cognitive and Somatic symptoms, termed 


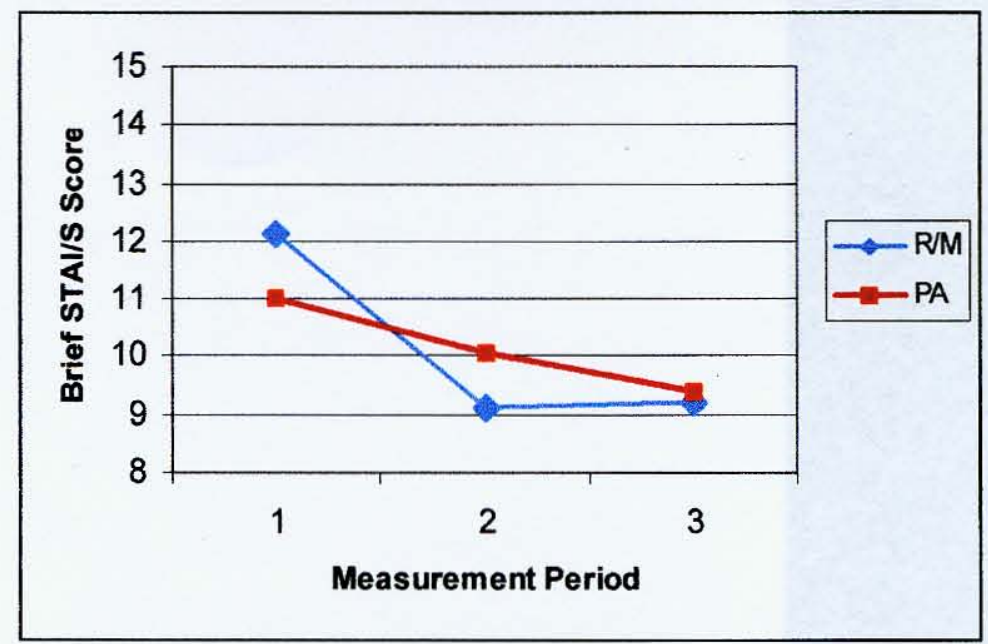

Note: Period 1 = Baseline; 2 = Immediate Post; 3 = Final

Fig. 1. Mean Brief STAI-S Scale Scores by Intervention by Measurement Period 


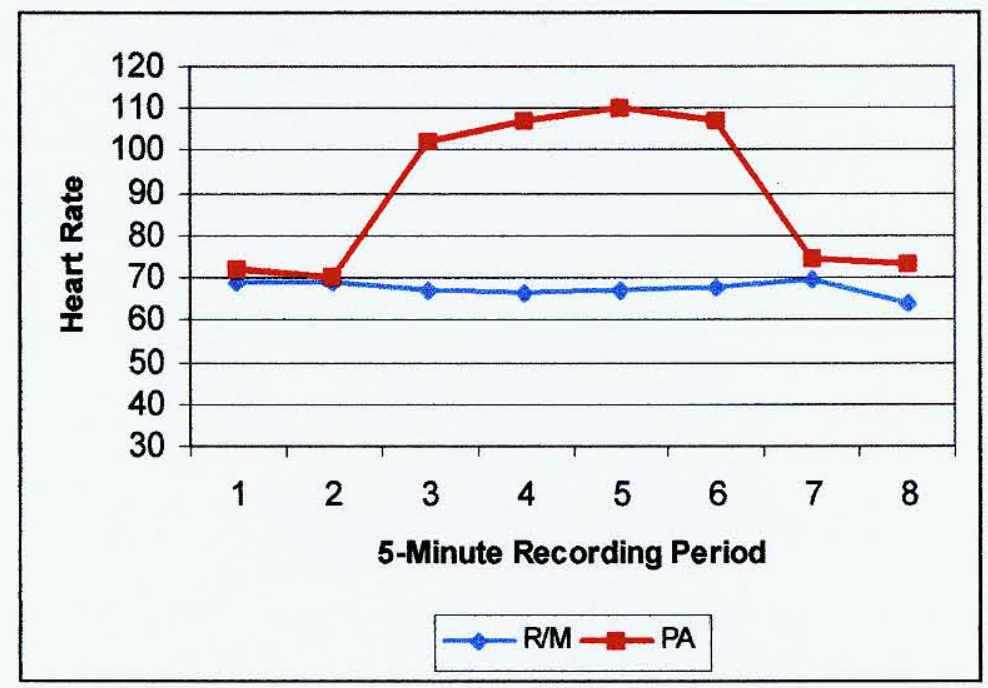

Fig. 2. Mean HR Values by Intervention for 8 Five-Minute Measurement Periods 
'csaqdif'. A negative value would signify more somatic than cognitive symptoms, whereas a positive value would indicate that cognitive symptoms predominate. Overall, values of this variable ranged from -18 to +11 . Next, the mean and standard deviation of the distribution of 'csaqdif' was calculated for each intervention (exercise and relaxation) and the scores standardized (i.e. transformed into a distribution with mean $=0$ and s.d. $=$ 1). These standardized scores were then correlated with a variable (staisdif) reflecting the difference between pre- and post-intervention STAI/State (full) inventories, a measure of change in negative affect. Support for this hypothesis would be reflected in the following correlation patterns: For relaxation, a positive relationship between csaqdif and staisdif, such that the greatest pre- to post-intervention change in negative symptom reduction (staisdif) would be associated with a positive csaqdif score (indicating a preponderance of cognitive anxiety symptoms). For exercise, these two variables would be predicted to have a negative correlation, such that greater improvement in negative affect (staisdif) would be associated with lower csaqdif scores, a sign of predominantly somatic symptoms. Partial support for this hypothesis was found in terms of a highly significant, positive correlation $(\mathrm{r}=.594, \mathrm{n}=16, \mathrm{p}=.015)$ between standardized csaqdif and staisdif scores for the R/M intervention. However, the predicted negative correlation between these two variables did not emerge for PA; the correlation was non-significant and slightly positive $(\mathrm{r}=.273, \mathrm{n}=22, \mathrm{p}=.220)$ Scatter plots for these two correlations are presented in Figures $3(\mathrm{R} / \mathrm{M})$ and $4(\mathrm{P} / \mathrm{A})$. 


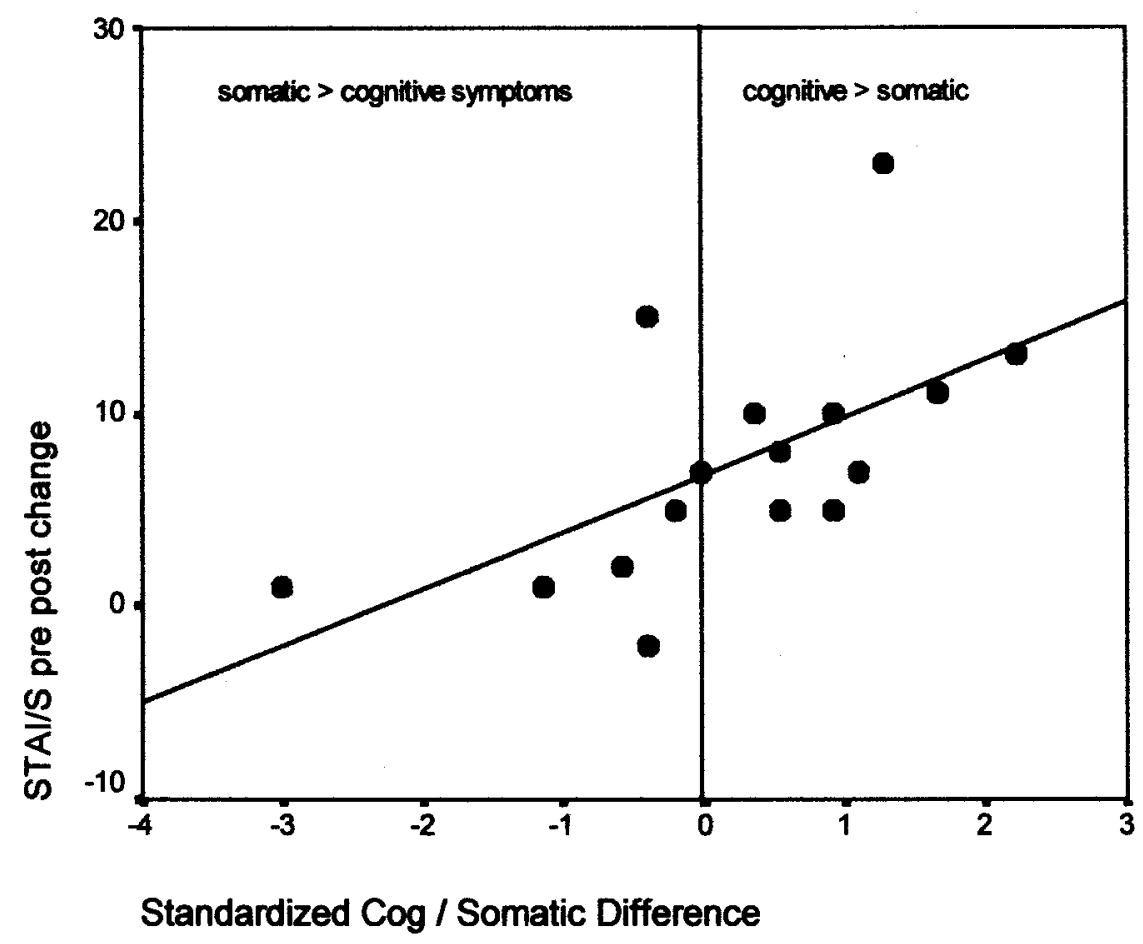

Note: $\mathrm{r}=.594, \mathrm{p}=.015, \mathrm{n}=16$

Figure 3. Scatter Plot: Standardized CSAQ Difference Scores by Pre- to Post-Intervention STAI/State Scores for R/M 


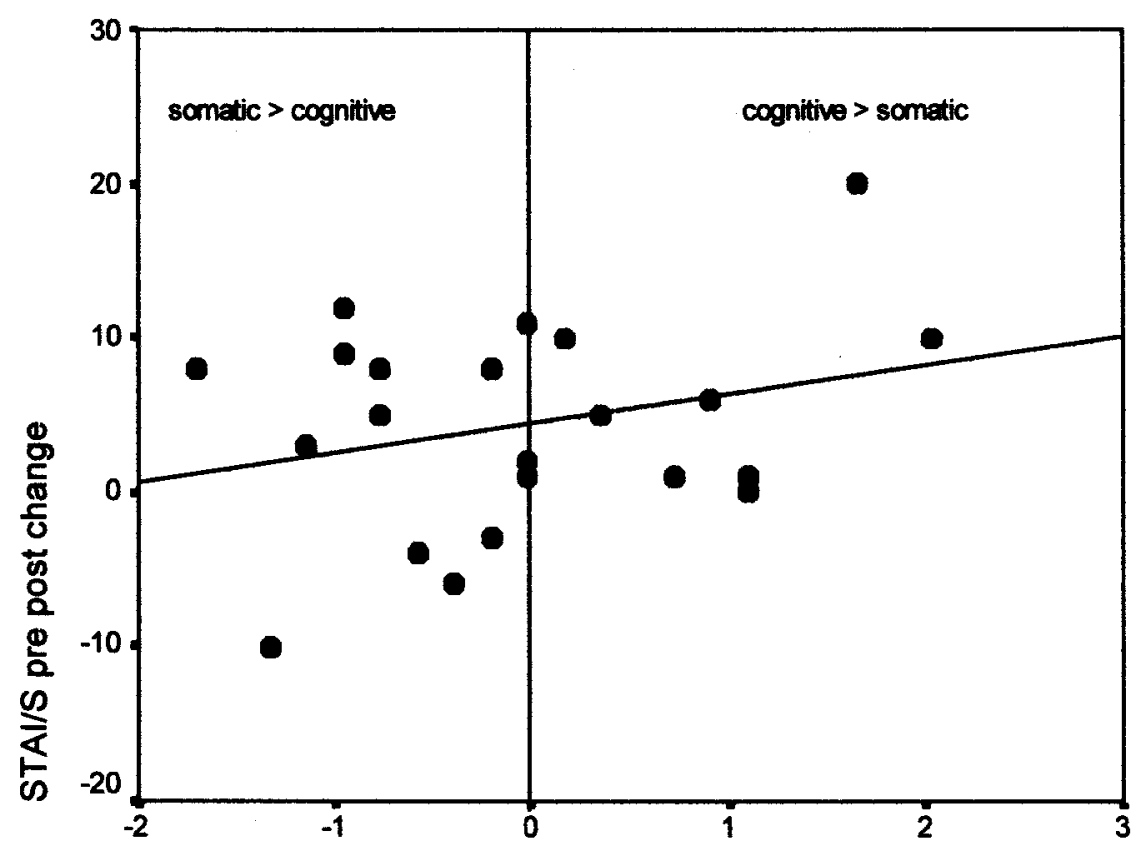

Standardized Cog / Somatic Difference

Note: $\mathrm{r}=.273, \mathrm{p}=.220, \mathrm{n}=22$

Figure 4. Scatter Plot: Standardized CSAQ Difference Scores by Pre- to Post-Intervention STAI/State Scores for PA 


\section{DISCUSSION}

Results of this study are discussed in two sections, reflecting the two study hypotheses. Overall, there is strong evidence that brief, single bouts of both PA and R/M are capable of inducing changes in affect state, and at least in this instance appear to do so to approximately comparable degrees. There is also partial support for the prediction of differential effects of PA and R/M on negative affect reduction as a function of anxiety symptoms that are predominantly cognitive or somatic in nature.

Overall Effects of Exercise \& Relaxation on Affect: For all key outcome measures, including the PANAS Positive and Negative Affect Scales, Spielberger STAI/State (brief and full version), and heart rate, mean values assessed during baseline data collection were within average or normal ranges, suggesting that any subsequent changes probably do not reflect the effect of simple regression toward the mean. It was predicted that both the PA and R/M interventions would have significant effects on selfreported affect ratings. This prediction was largely confirmed, although the direction of

effect for one variable -- Positive Affect -- was opposite to that predicted. Participants in the PA condition reported significantly lower levels of negative affect, measured by both the Spielberger STAI/State Scale (brief version) and the PANAS Negative Affect Scale. However, positive affect, as measured by the PANAS Positive Affect scale, also declined significantly. The $\mathrm{R} / \mathrm{M}$ intervention appeared to have comparable, though not identical 
effects on self-rated affect, as reflected in significantly lower STAI/State Scale (brief version) scores and significantly reduced Positive Affect Scale scores. Scores on the PANAS Negative Affect Scale also declined, but to only a marginal $(p=.06)$ degree.

The significant reduction in negative affect found here is consistent with studies reviewed in the introduction attesting to the tension-reducing characteristics of both PA and R/M, as summarized in Petrozzello's meta-analysis (Petruzzello, Landers et al. 1991). Both appear to reduce psychological and physiological (i.e. sympathetically-driven) activation, though undoubtedly via different mechanisms. The significance of the present findings lies in the fact that this is one of relatively few studies to directly compare the effects of PA and R/M using a sample of individuals -- college students -- who are not either especially physically active or "true believers" / practitioners of meditation or relaxation techniques. The exercise intervention -- self-paced treadmill walking -- was selected as being highly accessible to individuals of wide-ranging fitness levels. Use of a self-selected walking pace accentuated this factor, in a manner consistent with results of a recent study by Szabo (Szabo, Mesko et al. 1998). Perhaps the most interesting aspect of this finding is that both interventions appeared capable of reducing negative affective states in the short term, without ongoing, regular practice. The concept of 'time out' from other, potentially stressful circumstances -- previously suggested as one way in which PA in particular may reduce tension and promote psychological restoration (Plante 1999); (Breus and O'Connor 1998) -- may be relevant here. Not only do both interventions offer a respite from ongoing activities, but they also result in altered states of physiological activation (i.e. hyper- or hypoarousal which may accentuate the sense of being 'disconnected' from habitual behavior patterns by virtue of a contrast effect. In effect, this 
reflects the importance of being attuned to phasic activity, synchronized with natural physiological rhythms as a way of balancing productive engagement with restorative rest or activity, as formally conceptualized by Stoyva (Stoyva and Carlson 1993) and more recently popularized by Loehr and Schwartz (Loehr and Schwartz 2003).

The unexpected finding of lower scores on the PANAS Positive Affect Scale in both conditions is important to consider, and may be related to several factors. Consider first the concept of 'positive affect' as described by Watson, Clark and Tellegen (Watson, Clark et al. 1988), which "...reflects the extent to which a person feels enthusiastic, active, and alert." (p.1063). Although pre- and post-intervention scores on this scale differed significantly, in both instances they were in a mid-to high range, well above the bottom of the scale, characterized as reflecting "sadness and lethargy". Baseline Positive Affect Scale scores averaged 30.31, $(\mathrm{PA}=31.08, \mathrm{R} / \mathrm{M}=29.55)$, comparable to the value of 29.7 ('present moment' ratings) reported for college students by Watson, Clark and Tellegen. In the PA condition, Positive Affect scores declined only to 28.1, whereas those in the $\mathrm{R} / \mathrm{M}$ condition declined to 23.8 , which is somewhat lower than reference values.

Perhaps the most reasonable explanation for these results is that the concept of 'positive affect', as defined by Watson, Clark and Tellegen, emphasizes arousal or activation, implied by such terms as 'enthusiastic', 'active', and 'alert'. The effects of both PA and R/M, measured immediately after a period of quiet rest following either intervention are very likely to have attenuated any such state of activation, resulting in a lower, but still positive, overall level. There may be a tendency in the orientation of these authors to attribute positive affective qualities to states of activation that imply high levels of energy and alertness. However, it is important not to overlook the fact that, at 
least from a subjective standpoint, 'pleasant' affective states could just as readily involve lower levels of activation without connoting a state of depression or sadness. Consider, for example, a meditative state involving highly focused, yet relaxed attention as described in the context of mindfulness (Kabat-Zinn 1982). The explanation favored here for the finding that scores on both the PANAS Positive and Negative Affect Scales declined (along with the brief Spielberger STAI/S Scale) is that, in the aftermath of both interventions, participants experienced a perceived state of reduced tension and lower activation.

Whether or not such results would apply in the 'real world' is another matter, however. The laboratory setting provided a context that probably reinforced a sense of relaxation and low physiological activation. The initial curiosity and even slight apprehension expressed by some participants at the outset of the experiment may have gradually given way to a sense of comfort and maybe even, in some instances, boredom. Requesting that eighteen-year-old undergraduates listen to a relaxation tape or walk on a treadmill for twenty minutes may be discrepant with what one might otherwise do at this age to relieve stress outside the context of a research study. To consider one specific issue, walking on a treadmill in a laboratory versus walking outdoors in a environment offering greater sensory stimulation might well be expected to have a differential impact on how one feels. Indeed, research by Ekkakakis cited earlier corroborated the hypothesis that taking even short walks can have positive effects on affective states. Results of the present study could be interpreted as indicating that either increases or decreases in physiological state induced via controlled laboratory interventions may be associated with reduced feelings of tension and negative affect, but that in order to promote more 
positive, energetic responses, at least as measured by the PANAS, more stimulating interventions should be considered if the goal is to actually increase activation and energy level.

Differential Effects of PA vs R/M: The second hypothesis predicted that PA and $\mathrm{R} / \mathrm{M}$ would have differential effects in terms of reducing negative affect depending on the domain in which participants experience anxiety symptoms. To evaluate this hypothesis, the Cognitive Somatic Anxiety Questionnaire (CSAQ) was administered at baseline, and scored to determine whether anxiety symptoms were predominantly cognitive or somatic in nature by subtracting the 'Somatic Symptoms' total score from the 'Cognitive Symptoms' total. Thus, a negative value of this variable indicated that somatic symptoms were in the majority, whereas a positive value signified that cognitive symptoms were more numerous. A score of zero meant that somatic and cognitive symptoms were equivalent in number. For each intervention (PA and $\mathrm{R} / \mathrm{M}$, this difference score was standardized (i.e. mapped into a distribution with mean $=0$ and standard deviation $=1$ ), and the resulting scale was correlated with a variable reflecting changes in STAI-State Anxiety scores. This latter variable was computed by subtracting STAI-State post scores from those obtained at baseline. In this case, a negative value indicated that postintervention STAI scores were greater than those obtained at baseline; a positive value that post-intervention scores were lower, and a score of zero that post-intervention scores were unchanged.

Pearson product-moment correlations were computed between these two variables for each intervention, as described in the Results section. Concerning the relaxation condition, based on Schwartz, Davidson, and Goleman's original hypothesis (Schwartz 
1978), it was predicted that this cognitively-oriented intervention would be associated with greater pre- to post-intervention anxiety or negative affect than would PA, which is more somatically-oriented. The highly significant, positive correlation that was obtained was consistent with this hypothesis. This correlation indicated that as the CSAQ variable became increasingly positive (indicating an increasing preponderance of cognitive anxiety symptoms), the difference between pre- and post-intervention STAI-State scores also increased. In other words, it appears that participants who report more cognitive than somatic anxiety symptoms experienced a greater reduction in anxiety symptoms in response to $\mathrm{R} / \mathrm{M}$ with its strong cognitive orientation.

With respect to PA, it was predicted that a CSAQ pattern in which somatic symptoms predominated (i.e. low, negative scores), would be associated with the greatest pre- to post-intervention change in STAI-State scores. In effect, the prediction would be for a negative correlation between the two variables, just the opposite of that predicted and obtained for R/M. Results of this analysis were non-significant, with the correlation coefficient being slightly positive. In failing to reject the null hypothesis of no effect, this analysis does not appear to offer any significant interpretive clues. Given the positive correlation coefficient associated with both analyses, it may be that the effects of both interventions are more pronounced when cognitive symptoms predominate.

Overall, the analysis and interpretation of this hypothesis is compromised by methodological issues. First, the CSAQ asks participants to rate anxiety symptoms at times when they are anxious, rather than at the present time. This necessitates a selfrating based on how one feels at other times, given that very few participants indicated highly elevated anxiety levels in any of the 'present moment' questionnaires. Second, the 
CSAQ and Spielberger STAI-State scales do not share any common conceptual basis in terms of a model of anxiety. They are distinct inventories that were developed and applied in different research situations, and as a result may not be especially well suited to an analysis of change scores in anxiety level as a function of anxiety symptom domain. Nevertheless, partial support for the hypothesis of a differential effect of treatment by symptom domain suggests that this may be a fruitful area for further research.

Results of this study appear consistent with evidence that relatively brief, 'selfmanagement' strategies consisting of either PA or R/M can have measurable effects on affective states. The effects of the two interventions are clearly evident in an inspection of Figure 1 (p.34), which plots ratings on the brief Spielberger STAI-State scale over baseline, immediate-post intervention, and final rating periods. Despite attaining very different levels of physiological activation, participants in both interventions ended up at very nearly identical points by the end. Statistical analysis of this trend revealed both a significant interaction of time by intervention condition, such that STAI ratings from baseline to immediate post-intervention decreased more rapidly following $\mathrm{R} / \mathrm{M}$ than PA. This finding reflects two factors: First, baseline STAI scores were slightly higher in the $\mathrm{R} / \mathrm{M}$ condition; and second, STAI-State scores immediately following R/M were lower than those following PA. Such findings are consistent with research by Ekkakakis and others (Ekkekakis, Hall et al. 2000) suggesting that STAI measures taken immediately post-exercise are confounded with residual exercise-related physiological activation. The fact that STAI/State scores continued to decline slightly during the final ten-minute period following PA supports this observation. 
That the two interventions succeeded in their aim of inducing differential states of physiological activation is evident in Figure 2 (p.35), which plots heart rate over time for each intervention. Mean scores for each of eight five-minute intervals: Baseline 1 and 2; Intervention 1, 2, 3, and 4; and post-intervention 1 and 2 . Heart values were comparable for both interventions during the entire baseline period, averaging approximately 70 beats per minute. During the intervention phase, HR values increased significantly in the PA condition and either remained constant or declined slightly (thought not to a statistically significant degree) in the $\mathrm{R} / \mathrm{M}$ condition. During the final, post-intervention phase, $\mathrm{HR}$ values remained relatively constant following $\mathrm{R} / \mathrm{M}$ and had returned to very near baseline levels following PA.

This study evaluated affective responses to PA and R/M using treadmill walking and a standardized relaxation/meditation technique. It was based on earlier research investigating the anxiolytic effects of both PA and R/M on anxiety, which is of obvious clinical significance. However, it also examined the degree to which these intervention might have a more positive effect on affect states, or affect enhancement. Results suggested that, at least in terms of the measure selected for this purpose -- the PANAS -that a state of reduced activation may actually have contributed to an apparent decline in positive affect. Subsequent research will undoubtedly employ other scales that are not so dependent on the construct of activation as a component of positive affect.

Overall, results of this study are consistent with previous research demonstrating that PA has a significant impact on negative affect states, and that even relatively brief, acute exercise sessions - 20 minutes of cycle ergometry, for example (Raglin and Wilson 1996) - can have a measurable and significant impact. Much of the early research in this 
area was conducted with highly conditioned athletes exercising at high intensity levels (Bahrke and Morgan 1978); (Raglin and Morgan 1985); (Petruzzello, Landers et al. 1991), and the assumption seemed to be that one needed to cross a threshold of exercise intensity and duration in order to derive any such psychological benefit.

However, more recently, studies have shown that PA has demonstrable psychological benefits for more broadly representative samples of the general population, as exemplified by the research of Ekkakakis and colleagues (see, for example (Ekkekakis, Hall et al. 1999; Ekkekakis and Petruzzello 1999; Ekkekakis and Petruzzello 2000; Ekkekakis and Petruzzello 2001; Ekkekakis and Petruzzello 2002)). This research is significant for several reasons. First, it questions the historical reliance on a single measure of negative affect - the Spielberger STAI/State Anxiety Scale - in countless studies addressing the psychological benefits of PA and advocates a broader view that includes positive effects as well. Second, it calls for a tighter integration between empirical studies and conceptual models that could account for the beneficial psychological effects of PA. Finally, and perhaps of greatest interest, is evidence from this line of research that relatively brief, low-intensity bouts of PA have measurable psychological effects having little correlation with physiological intensity and conditioning.

Consistent with such evidence, Plante argued convincingly that the overall benefits of PA for many (if not most) individuals probably reflect psychologically-based perceptions of feeling states and cognitive appraisals having relatively little bearing on physiological activation levels (Plante 1999). A very recent study by Szabo nicely supports this viewpoint. This study investigated the affective responses of male and 
female college students to 20 minutes of running or jogging at a self-selected pace (Szabo 2003). Overall results revealed a significant reduction in the Total Mood Disturbance (TMD) score of the Profile of Mood States (POMS). Significantly, there was no significant correlation between the magnitude of change on the POMS TMD score and exercise intensity, as assessed by percent of maximal heart rate reserve.

Similarly, the present study found evidence of a significant reduction in negative affect states (PANAS Negative Affect Scale, Spielberber STAI/State Scale) comparable to those associated with a clinical R/M technique (the Body Scan) when college students walked on a treadmill at a self-selected pace for 22 minutes. The maximum speed recorded was 3.6 miles per hour, the minimum 1.8 , with a mean of 2.76 . On average, they covered a distance of .88 miles. For the PA group overall, the mean percentage of Heart Rate Reserve (HRR) represented by the average maximum HR attained was calculated, based on a mean sample age of 20.27, mean HRmax $=109.11$ (mean HR for the third, most intense phase of the exercise intervention prior to tapering speed), and mean HRrest $=70.88$ :

$$
\begin{aligned}
& H R R=H R \max -H R r e s t \\
& H R R=(220-20 \text { (mean age }))-71(\text { HRmean resting })=200-71=129 \text { beats } / \text { min } \\
& 109 \text { (HRavg.max })=71 \text { (HRavg.rest })+38:
\end{aligned}
$$$$
38 / 129=29.5 \% \text { or approximately } 30 \% \text { HRR }
$$

These calculations demonstrate that, on average, participants in the PA condition were exercising at a relatively low level of intensity, approximately $30 \%$ of $\mathrm{HRR}$, below the recommended level for aerobic exercise benefit (e.g. 60-80\%) (American College of Sports Medicine 2001). Furthermore, the level of self-paced walking reported here 
appears to be of an intensity more in keeping with that recommended by the Surgeon General's 'Exercise Lite' guidelines, calling for 20-30 minutes of cumulative, moderate intensity PA most days of the week (US Department of Health and Human Services 1996). The fact that even brief bouts (i.e. 10-20 minutes) of PA may be linked to measurable affect changes (reduced anxiety, stress, etc.) simply reinforces the potential benefits of this recommendation.

As far as exercise intensity was concerned, the level attained was actually in the 'Low', rather than 'Moderate' (i.e. 'Exercise Lite') range. This was determined using ACSM guidelines for classifying PA intensity (ACSM 2000, Table 7-2, p.150) and is based on the obtained average HRR value of approximately $30 \%,(<20 \%$ is classified as 'very light'; between 40 and $59 \%$ is 'moderate').

Further underscoring the modest energy expenditure associated with self-paced walking in this study is the average metabolic (MET) level for the PA group. This was estimated for PA participants as a group, using ACSM's VO2 equation for walking (ACSM 2000, p.303), and calculating the average Metabolic Equivalent (MET) value as follows:

$$
\begin{aligned}
& \mathrm{VO} 2=.1 \times \text { speed }(\mathrm{meters} / \mathrm{min})+(1.8 \times \text { speed } \times \text { grade })+3.5 \mathrm{ml} * \mathrm{~kg}^{*} \mathrm{~min}-1 \\
& \mathrm{VO} 2=.1 \times(2.76 \mathrm{miles} / \mathrm{hr} \times 26.8 \text { meters } / \mathrm{min})+0+3.5 \mathrm{ml} \mathrm{kg}^{*} \mathrm{~min}-1 \\
& \mathrm{VO} 2=.1 \times 73.97+3.5=7.4+3.5=10.9, \text { approximately } 11 \mathrm{ml}{ }^{*} \mathrm{~kg}^{*} \mathrm{~min}-1 \\
& 11 \mathrm{ml}{ }^{*} \mathrm{~kg}^{*} \mathrm{~min}-1 / 3.5=3.11 \mathrm{METS}
\end{aligned}
$$

This value is consistent with ACSM estimates for energy requirements in METS (ACSM $2000 \mathrm{p} 307$, Table D-3) for a walking speed between 2.5 and $3.0 \mathrm{miles} / \mathrm{hr}$, and, consistent with exercise intensity based on average the average HRR, suggests a rather minimal 
expenditure of energy, well within the range many individuals functioning at low levels of conditioning.

The fact that on average, participants experienced a significant change in affect at a rather low exercise intensity level is compatible with increasing evidence that psychological and physiological benefits of PA are not necessarily highly correlated, as well as with other evidence that the psychological effects of PA may be attainable at relatively low levels of exercise intensity. Consistent with results of the Szabo study, neither individualized measure of exercise intensity in this study (maximum speed / distance covered) correlated significantly with self-reported changes in positive $(r=.14$ / .21 , n.s.), negative $(r=.04 / 0.00$, n.s.), or anxiety-related $(r=-.05 /-.08$, n.s.) affect states. Results such as these suggest that it may be necessary to re-think the commonly held dictum that exercise intensity is a key factor in determining the magnitude of change in psychological variables such as affect. Instead, as suggested by Plante (Plante 1999) and Szabo (Szabo 2003), cognitive appraisal processes may be the key to interpreting self-reported changes in affect states following PA. In this study, participants controlled the pace of walking, which may by itself constitute an important factor in promoting a sense of psychological well-being. 


\section{SUMMARY AND CONCLUSIONS}

Results of this study suggest that single, brief sessions of self-paced, low to moderate intensity PA had measurable and significant effects on self-report measures of affect in undergraduate females. Participants randomly assigned to either PA (treadmill walking) or R/M ('Body Scan') interventions reported reductions in negative affect (PANAS Negative Affect Scale and brief Spielberger STAI/State Anxiety Scale), as well as reduced Positive Affect (PANAS Positive Affect Scale), the latter interpreted as indicating a post-intervention reduction in overall activation. Of particular note is the finding that PA resulted in a level of affect change comparable to that attained by R/M.

Partial support was obtained for the hypothesis that R/M and PA may have differential effects on State Anxiety ratings, in terms of evidence that participants for whom cognitive anxiety symptoms predominated experienced a greater reduction in State Anxiety in the cognitively-oriented R/M condition. This was consistent with the early hypothesis of Davidson et al (Davidson and Schwartz 1976) that matching anxiety symptom domain to intervention domain (i.e. either cognitive or somatic) would result in the most beneficial effect. However, PA did not appear to maximize anxiety symptom reduction in participants for whom somatic symptoms predominated. Thus, the Davidson et al hypothesis received only partial, qualified support. 
From a methodological standpoint, this study could benefit from several refinements. First, measures of positive change in emotional state need to be selected that are independent of activation level; this is not characteristic of the PANAS Positive Affect Scale, and may account for the finding of lowered Positive Affect. Second, further consideration should be given to selection of appropriate participants for these interventions. Despite overall significant findings, changes in affect ratings as a function of either treadmill walking or listening to a relaxation/meditation tape are not necessarily activities that freshmen-level college students would necessarily self-select as means of reducing stress or anxiety. Currently, both interventions are more commonly employed with older, frequently de-conditioned individuals, and it is possible that an even more pronounced contrast in outcome effects might be obtained with such a sample. More research is warranted to document mounting evidence that the psychological benefits of PA are broadly available to individuals of varying levels of physical conditioning exercising at differing intensity levels. For many years, the benefits of exercise have been touted as available to those who are willing to put in the time and effort necessary to achieve high levels of conditioning. Unfortunately, this message may have had the effect of making such benefits appear to be out of reach for the average person who is unable or unwilling to make such sacrifices. Increasingly, however, there are indications that even very simple activities - walking as an especially notable example - are capable of fostering immediate changes in emotional state (affect) in the absence of high levels of physical conditioning. In all likelihood, encouraging people to walk or otherwise exercise as a pace that feels subjectively comfortable, rather than dictating or prescribing a set pace can help contribute to a sense of psychological well 
being by fostering a sense of self-control and self-efficacy. The degree to which PAbased psychological well being, independent of actual aerobic conditioning, could translate into the kinds of health benefits traditionally associated with regular exercise, remains to be determined, as proposed by Plante (Plante 1999). It is a provocative idea, but increasing emphasis on mind/body interactions makes it plausible to hypothesize that very simple physical and psychological interventions may in fact represent different paths to a common outcome of enhanced health and well-being. Future research in this area should emphasize interactions between psychological appraisal processes and physical exertion to assess the overall impact of self-management strategies including PA and $\mathrm{R} / \mathrm{M}$. This is an especially important consideration with individuals having limited exercise experience or opportunities, or medical patients. Establishing a long-term commitment to exercise, it would seem, should begin with an emphasis on positive, 'here and now' psychological benefits that appear to be attainable even at extremely modest levels of physical exertion, perhaps even below the levels deemed necessary to achieve health-protective effects. The potential for immediate, positive effects -- i.e. simply 'feeling better' -- of even low intensity PA may be a source of positive reinforcement all too easily overlooked by those who ascribe either to the prescriptive or the "no pain / no gain' perspectives on exercise. 


\section{REFERENCES}

ACSM (2000). ACSM's guidelines for exercise testing and prescription. Philadelphia, Lippincott Williams and Wilkins.

American College of Sports Medicine (2001). ACSM's Health and Fitness Certification Review. Philadelphia, Lippincott Williams \& Wilkins.

Bahrke, M. S. and W. P. Morgan (1978). “Anxiety reduction following exercise and meditation." Cognitive Therapy \& Research 2(4): 323-333.

Baine, M. J. (1999). Meditation and mindfulness. Essentials of complementary and alternative medicine. W. B. Jonas and J. S. Levin. Philadelphia, Lippincott Williams \& Wilkins: 522-536.

Balke, B. and R. W. Ware (1959). "An experimental study of physical fitness of Air Force personnel." U.S. Armed Forces Medical Journal 10: 675-688.

Benson, H. (1975). The relaxation response. New York, William Morrow.

Benson, H. (1984). Beyond the relaxation response. New York, Times Books.

Berger, B. G. and R. W. Motl (2000). "Exercise and mood: A selective review and synthesis of research employing the Profile of Mood States." Journal of Applied Sport Psychology 12: 69-92. 
Bernstein, D. A., T. D. Borkovec, et al. (2000). New directions in progressive relaxation training: A guidebook for helping professionals. Westport, Connecticut, Praeger.

Borg, G. (1973). "Perceived exertion: A note on "history and methods"." Medicine and Science in Sports 5: 90-93.

Borg, G. (1998). Borg's perceived exertion and pain scales. Champaign, Illinois, Human Kinetics.

Boutcher, S. H. and D. M. Landers (1998). "The effects of vigorous exercise on anxiety, heart rate, and alpha activity of runners and non-runners." Psychophysiology 25(6): 696-702.

Breus, M. J. and P. J. O'Connor (1998). "Exercise-induced anxiolysis: a test of the "time out" hypothesis in high anxious females." Medicine and Science in Sports and Exercise 30(7): 1107-1112.

Buckworth, J. and R. K. Dishman (2002). Exercise psychology. Champaign, Illinois, Human Kinetics.

Davidson, R. J. and G. E. Schwartz (1976). The psychobiology of relaxation and related states: A multi-process theory. Behavior control and modification of physiological activity. D. I. Mostofsky. Englewood Cliffs, New Jersey, Prentice-Hall: 399-442.

DeGood, D. E. and R. C. Tait (1987). "The Cognitive-Somatic Anxiety Questionnaire: Psychometric and validity data." Journal of Psychopathology \& Behavioral Assessment 9(1) Mar 1987): 75-87. 
Delmonte, M. M. and G. M. Ryan (1983). "The Cognitive-Somatic Anxiety Questionnaire (CSAQ): A factor analysis." British Journal of Clinical Psychology 22(3): 209-212.

Dishman, R. K. (1992). Psychological effects of exercise for disease resistance and health promotion. Exercise and disease. R. R. Watson and M. Eisinger. Ann Arbor, CRC Press: 179-207.

Ekkekakis, P., E. E. Hall, et al. (1999). "Measuring state anxiety in the context of acute exercise using the State Anxiety Inventory: An attempt to resolve the brouhaha." Journal of Sport \& Exercise Psychology 21(3): 205-229.

Ekkekakis, P., E. E. Hall, et al. (2000). "Walking in (affective) circles: Can short walks enhance affect?' Journal of Behavioral Medicine 23(3): 245-275. Ekkekakis, P. and S. J. Petruzzello (1999). "Acute aerobic exercise and affect: current status, problems and prospects regarding dose-response." Sports Medicine. 28(5): 337-74.

Ekkekakis, P. and S. J. Petruzzello (2000). "Analysis of the affect measurement conundrum in exercise psychology I. Fundamental issues." Psychology of Sport \& Exercise 1: 71-88.

Ekkekakis, P. and S. J. Petruzzello (2001). "Analysis of the affect measurement conundrum in exercise psychology: II. A conceptual and methodological critique of the Exercise-induced Feeling Inventory." Psychology of Sport \& Exercise 2(1): 1-26. 
Ekkekakis, P. and S. J. Petruzzello (2002). "Analysis of the affect measurement conundrum in exercise psychology: IV. A conceptual case for the affect circumplex." Psychology of Sport \& Exercise 3(1): 35-63.

Endler, N. S. and N. L. Kocovski (2001). "State and trait anxiety revisited." Journal of Anxiety Disorders 15(3): 231-245.

Freedland, K. E. and R. M. Carney (1988). "Factor analysis of the Cognitive-Somatic Anxiety Questionnaire.” Journal of Psychopathology \& Behavioral Assessment 10(4): 367-375.

Heimberg, R. G., D. Gansler, et al. (1987). "Convergent and discriminant validity of the Cognitive-Somatic Anxiety Questionnaire in a social phobic population." Behavioral Assessment 9(4): 379-388.

Howley, W. T. and B. D. Franks (1997). Health fitness instructor's handbook. Champaign, Illinois, Human Kinetics.

Jacobson, E. (1938). Progressive relaxation. Chicago, Illinois, University of Chicago Press.

Kabat-Zinn, J. (1982). “An outpatient program in behavioral medicine for chronic pain patients based on the practice of mindfulness meditation: theoretical considerations and preliminary results." Gen Hosp Psychiatry 4(1): 33-47.

Kabat-Zinn, J. (1990). Full catastrophe living: Using the wisdom of your body and mind to face stress, pain, and illness. New York, Delta.

Kabat-Zinn, J., L. Lipworth, et al. (1987). "Four-year follow-up of a meditation-based program for the self-regulation of chronic pain: Treatment outcomes and compliance.” The Clinical Journal of Pain 2: 159-173. 
Kabat-Zinn, J., Lipworth, L., and Burney, R. (1985). "The clinical use of mindfulness meditation for the self-regulation of chronic pain." Journal of Behavioral Medicine 8: 163-190.

Kabat-Zinn, J., A. O. Massion, et al. (1998). Meditation. Textbook of psycho-oncology. J. C. Holland. Oxford, Oxford University Press: 767-779. Kabat-Zinn, J., A. O. Massion, et al. (1992). "Effectiveness of a meditation-based stress reduction program in the treatment of anxiety disorders." American Journal of Psychiatry 149(7): 936-943.

Kabat-Zinn, J., E. Wheeler, et al. (1998). "Influence of a mindfulness meditation-based stress reduction intervention on rates of skin clearing in patients with moderate to severe psoriasis undergoing phototherapy (UVB) and photochemotherapy (PUVA)." Psychosom Med 60(5): 625-32.

Kaplan, K. H., D. L. Goldenberg, et al. (1993). "The impact of a meditation-based stress reduction program on fibromyalgia." Gen Hosp Psychiatry 15(5): 284-9.

Lehrer, P. M. and R. L. Woolfolk (1982). "Self-report assessment of anxiety: Somatic, cognitive, and behavioral modalities." Behavioral Assessment 4(2): 167-177.

Lichstein, K. L. (1988). Clinical relaxation strategies. New York, John Wiley \& Son.

Loehr, J. and T. Schwartz (2003). The power of full engagement: Managing energy, not time, is the key to high performance and personal renewal. New York, Free Press. 
Long, B. C. and R. van Stavel (1995). "Effects of exercise training on anxiety: A meta-analysis." Journal of Applied Sport Psychology 7(2): 167-189.

Massion, A. O., J. Teas, et al. (1995). "Meditation, melatonin and breast/prostate cancer: hypothesis and preliminary data." Medical Hypotheses 44(1): 39-46.

McAuley, E. and Mihalko (1998). Measuring exercise-related selfefficacy. Advances in sport and exercise psychology measurement. J. L. Duda. Morgantown, West Virginia, Fitness Information Technology: 371-390.

McNair, D. M., M. Lorr, et al. (1992). Profile of Mood States manual. San Francisco, Education and Industrial Testing Service.

Morgan, W. P., Ed. (1997). Physical activity and mental health. Washington, D.C., Taylor and Francis.

Morris, L. W., Davis, M. A., and Hutchins, C. H. (1981). "Cognitive and emotional components of anxiety: Literature review and a revised worryemotionality scale." Journal of Educational Psychology 73(541-555).

Noble, B. J. and R. J. Robertson (1996). Perceived exertion. Champaign, Illinois, Human Kinetics.

Petruzzello, S. J. (1995). “Anxiety reduction following exercise: Methodological artifact or "real" phenomenon?" Journal of Sport \& Exercise Psychology 17(1): 105-111.

Petruzzello, S. J., D. M. Landers, et al. (1991). "A meta-analysis on the anxiety-reducing effects of acute and chronic exercise. Outcomes and mechanisms." Sports Medicine. 11(3): 143-82. 
Plante, T. (1999). "Could the perception of fitness account for many of the mental and physical health benefits of exercise?" Advances in Mind-Body Medicine 15: 291-301.

Raglin, J. S. and W. P. Morgan (1985). "Influence of vigorous exercise on mood state." Behavior Therapist 8(9): 179-183.

Raglin, J. S. and W. P. Morgan (1987). "Influence of exercise and quiet rest on state anxiety and blood pressure." Medicine and Science in Sports and Exercise 19(5): 456-463.

Raglin, J. S. and M. Wilson (1996). "State anxiety following 20 minutes of bicycle ergometer exercise at selected intensities." International Journal of Sports Medicine 17(6): 467-471.

Rejeski, W. J., C. J. Hardy, et al. (1991). "Psychometric confounds of assessing state anxiety in conjunction with acute bouts of vigorous exercise." Journal of Sport \& Exercise Psychology 13(65-74).

Russell, J. A. (1980). “A circumplex model of affect." Journal of Personality \& Social Psychology 39(1-sup-6): 1161-1178.

Salmon, P. (1992). Cognitive-behavior therapy and musical performance anxiety. Casebook in cognitive behavior therapy. A. Freeman and F. Dattilio. New York, Plenum: 61-69.

Salmon, P. G., S. F. Santorelli, et al. (1998). Intervention elements promoting adherence to mindfulness-based stress reduction programs in the clinical behavioral medicine setting. Handbook of health behavior change. S. A. 
Shumaker, E. B. Schron, J. K. Ockene and W. L. McBee. New York, Springer: 239-266.

Schwartz, G. E., Davidson, R. J., and Goleman, D. J. (1978). "Patterning of cognitive and somatic processes in the self-regulation of anxiety: Effects of meditation versus exercise." Psychosomatic Medicine 40(4): 321-328.

Sime, W. E. (1984). Psychological benefits of exercise training in the healthy individual. Behavioral health: A handbook of health enhancement and disease prevention. J. Matarazzo, Weiss, S., Herd, J., Miller, N., and Weiss, S. M. New York, John Wiley: 488-508.

Smith, R. E., F. L. Smoll, et al. (1998). Measurement of trait anxiety in sport. Advances in sport and exercise psychology measurement. J. L. Duda. Morgantown, West Virginia, Fitness Information Technology, Inc.: 105-127. Speca, M., L. E. Carlson, et al. (2000). "A randomized, wait-list controlled clinical trial: The effect of a mindfulness meditation-based stress reduction program on mood and symptoms of stress in cancer outpatients." Psychosomatic Medicine 62(5): 613-622.

Spielberger, C. D. (1979). Understanding stress and anxiety. New York, Harper and Row.

Spielberger, C. D. (1983). Manual for the State-Trait Anxiety Inventory. Palo Alto, California, Consulting Psychologists Press.

Spielberger, C. D., R. L. Gorsuch, et al. (1970). Manual for the state-trait anxiety inventory (STAI). Palo Alto, California, Consulting Psychologists Press. 
Steptoe, A. and N. Kearsley (1990). "Cognitive and somatic anxiety." Behaviour Research \& Therapy 28(1): 75-81.

Stone, A. A. (1997). Measure of affective response. Measuring stress: A guide for health and social scientists. S. Cohen, R. C. Kessler and L. Underwood Gordon. New York, Oxford University Press: 148-171.

Stoyva, J. M. and J. G. Carlson (1993). A coping/rest model of relaxation and stress management. Handbook of stress: Theoretical and clinical aspects. $L$. Goldberger and S. Breznitz. New York, Free Press: 724-756.

Szabo, A. (2003). "Acute psychological benefits of exercise performed at self-selected workloads: Implications for theory and practice." Journal of Sports Science and Medicine (online) 2: 77-87.

Szabo, A., A. Mesko, et al. (1998). "Examination of exercise-induced feeling states in four modes of exercise." International Journal of Sports Psychology 29(4): 376-390.

Tabachnick, B. G. and L. S. Fidell (2001). Using multivariate statistics. Boston, Allyn and Bacon.

Tamaren, A. J., R. M. Carney, et al. (1985). "Predictive validity of the cognitive vs. somatic anxiety distinction." Pavlovian Journal of Biological Science 20(4): 177-180.

Teasdale, J., Z. V. Segal, et al. (2000). "Prevention of relapse/recurrence in major depression by mindfulness-based cognitive therapy." Journal of Consulting \& Clinical Psychology 68(4): 615-623. 
Tellegen, A. (1985). Structures of mood and personality and their relevance to assessing anxiety, with an emphasis on self-report. Anxiety and the anxiety disorders. A. H. Tuma and J. Maser. Hillsdale, New Jersey, Lawrence Erlbaum: 681-706.

Thorens, P., F. S. Floras, et al. (1990). "Endorphins and exercise: Physiological mechanisms and clinical implications." Medicine \& Science in Sports \& Exercise 22: 417-428.

US Department of Health and Human Services (1996). Physical activity and health: A report of the Surgeon General. Atlanta, Georgia, National Center for Chronic Disease Prevention and Health Promotion.

Watson, D., L. A. Clark, et al. (1988). "Development and validation of brief measures of positive and negative affect: the PANAS scales." Journal of Personality \& Social Psychology. 54(6): 1063-70.

Weissbecker, I., P. Salmon, et al. (2002). “Mindfulness-based stress reduction and sense of coherence among women with fibromyalgia." Journal of Clinical Psychology in Medical Settings 9(4): 297-307.

Wolpe, J. (1958). Psychotherapy by reciprocal inhibition. Stanford, California, Stanford University Press. 
APPENDIX A. : ASSESSMENT MEASURES 


\section{COGNITIVE-SOMATIC ANXIETY QUESTIONNAIRE (CSAQ)*}

Instructions: Please rate the degree to which you generally or typically experience this symptom when you are feeling anxious.

1. I find it difficult to concentrate because of uncontrollable thoughts

$\begin{array}{cc}1 & 2 \\ \text { Not at all } & \end{array}$

3
45
Very much

2. My heart beats faster

$\begin{array}{ccccc}1 & 2 & 3 & 4 & 5 \\ \text { Not at all } & & & & \text { Very much }\end{array}$

3. I worry too much over something that really doesn't matter

$\begin{array}{ccccc}1 & 2 & 3 & 4 & \begin{array}{c}5 \\ \text { Very much }\end{array}\end{array}$

4. I feel jittery in my body

1
Not at all

23

$4 \stackrel{5}{\text { Very much }}$

5. I imagine terrifying scenes

1
Not at all

2

3

$4 \quad 5$

6. I get diarrhea

1
Not at all

23
45
Very much

7. I can't keep anxiety provoking pictures out of my mind

$\begin{array}{ccccc}1 & 2 & 3 & 4 & \begin{array}{c}5 \\ \text { Very much }\end{array}\end{array}$

8. I feel tense in my stomach

1
Not at all

2

3

45

Very much

9. Some unimportant though runs through my mind and bother me

1
Not at all

23

45

Very much

10. I nervously pace

$\begin{array}{ccccc}1 & 2 & 3 & 4 & 5 \\ \text { Not at all } & & & & \text { Very much }\end{array}$

11. I feel like I am losing out on things because I can't make up my mind 1
Not at all

23
45
Very much

12. I become immobilized

1
Not at all

2

3

45

Very much

13. I can't keep anxiety-provoking thoughts out of my mind 1
Not at all 2

3

45

Very much

14. I perspire

1

Not at all

2.3
45
Very much

${ }^{*}$ Note: Cognitive items $=1,3,5,7,9,11,13$; Somatic items $=2,4,6,8,10,12,14$ 


\section{POSITIVE AND NEGATIVE AFFECT SCALE (PANAS)*}

This scale consists of a number of words that describe different feelings and emotions. Read each item and then mark the appropriate answer in the corresponding space. Indicate to what extent you feel this way right now. There are no right or wrong answers; rather, it's most important to simply indicate how you are feeling at the present time.

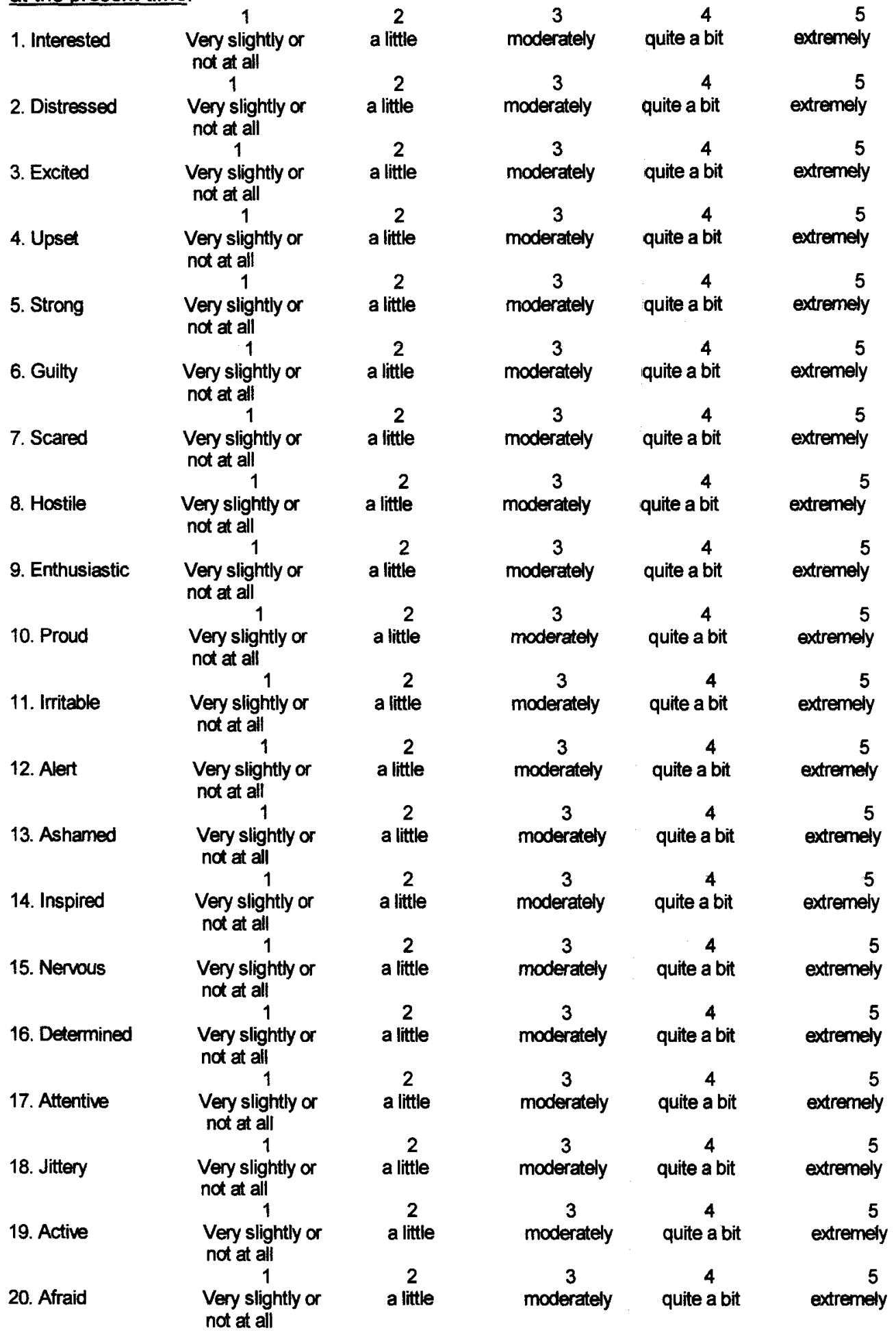

*Note: Positive Items: 1, 3, 5, 9,10, 12, 14, 16, 17, 19 Negative Items: 2, 4, 6, 7, 8, 11, 13, 15, 18, 20 


\section{STATE-TRAIT ANXIETY INVENTORY / STATE SCALE*}

\section{SELF-EVALUATION QUESTIONNAIRE}

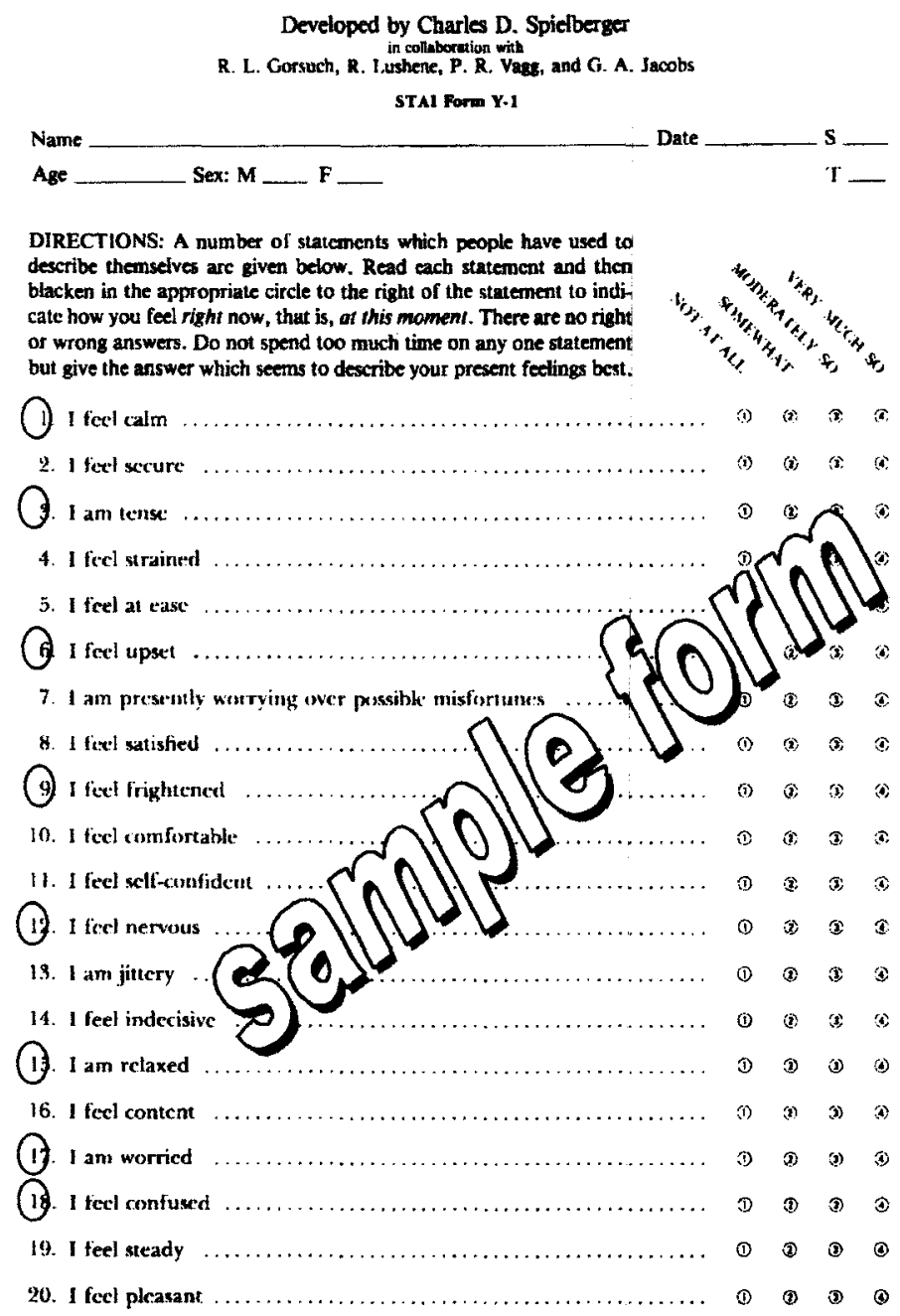

Consulting Psychologists Press

577 College Avenue, Fulo Alto, Californin 94306

*Note: Items $1,2,5,8,10,11,15,16,19, \& 20$ are reverse scored to compute the total

The STAI/S Brief form consists of the following eight items, each of which is circled above: $1,3,6,9,12,15,17$, and 18 . Items 1 and 15 are reverse scored. 


\section{STATE-TRAIT ANXIETY INVENTORY / TRAIT SCALE*}

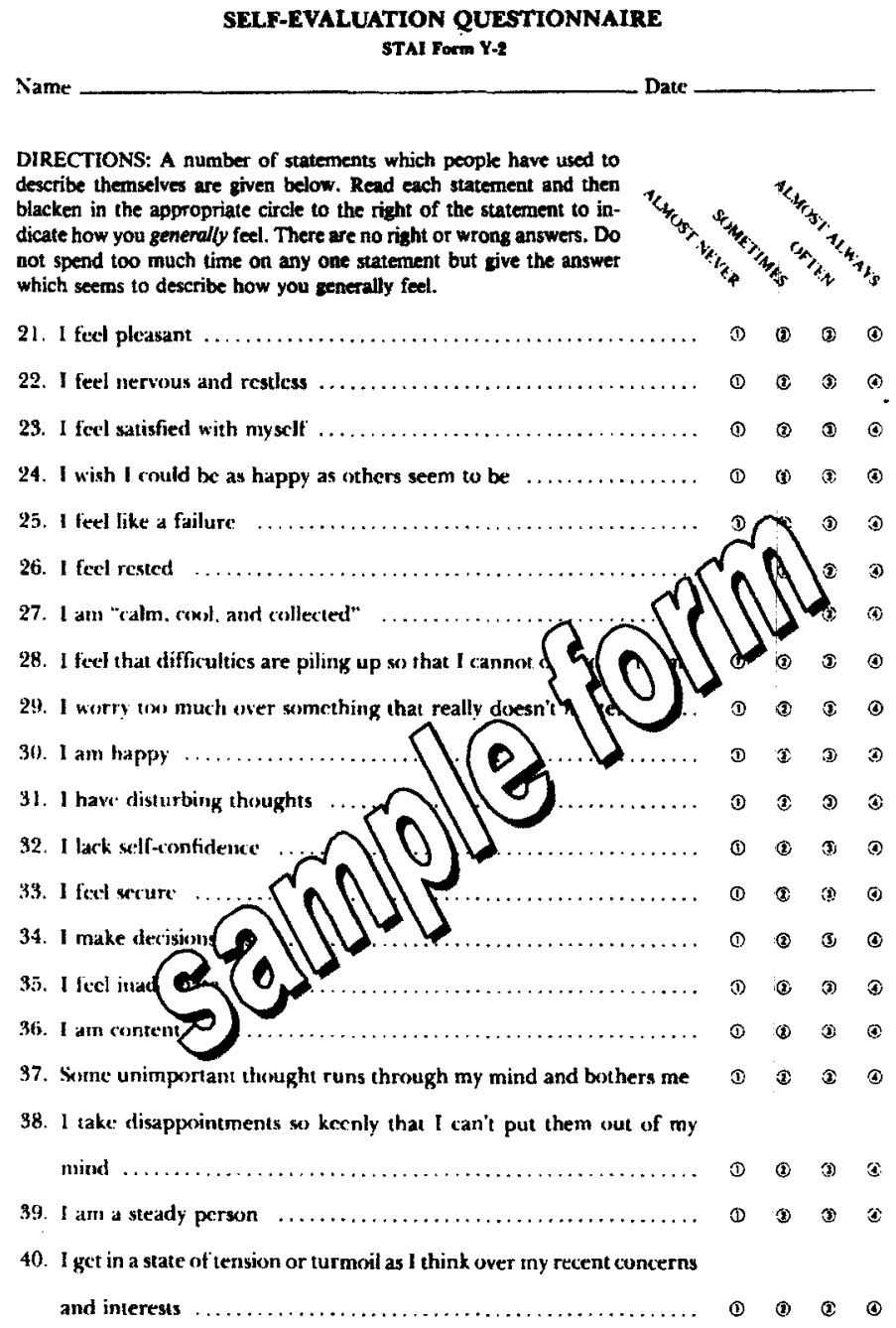

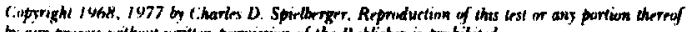

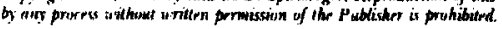

*Note: Items $21,23,26,27,30,33,34,36$, and 39 are reverse scored to compute total 
APPENDIX B: INFORMED CONSENT 


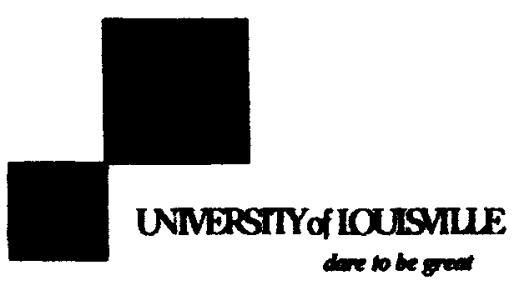

Danming o:

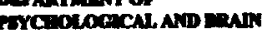
rations

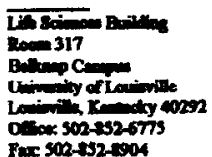

NFORMED CONEENT

A Comparieon of Brief Exorcies and Wodthtion-Baged Interventions for Cogrithe and Somntic Anxinty Symploms in Survwors of Breast Cancer

Introduction and Beckoround information

You are invited to participats in a reseerch study conducted under the idisection of Peul Selmon. Ph.D. The study is sponsored by the Universily of Loviovile Depertments of Paychological and Brain Sciences and Exerciso Physiology. The study will take plece in the Depertment of Poycholocicel and Brain Sciences (Ufte Sciences Building and Deviduon Heh) on the Uhiverity of Lovisville Bdiknep campus. Between 100 and 150 subjects will be imited to perticipede, epproximetely hel of whom mes survivors of breast cancer. Your participetion in this study will involve a briaf (15-20 minub) phone or foce-to-fece screaning interview. followed by a scheduled intervention seavion of approximataly 1.5 hours duration.

Pupose

The purpose of this research study is to compere two sectriounes for meneging streses and enviety often

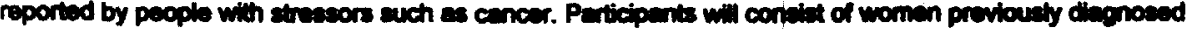
with and treeted for breast cancer within a two yeer period, as well as collogs-ope women without cancer.

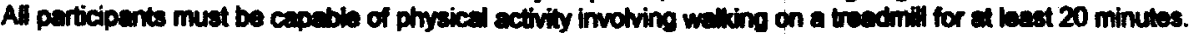

\section{Procectures}

Particlpation will invotwe a) a screening procedure; b) beceline teeting; c) a sinole seacion of either moderate intensidy exercise (welsing on a treadmill) or madition / rulocation; and d) find lacting. Whether

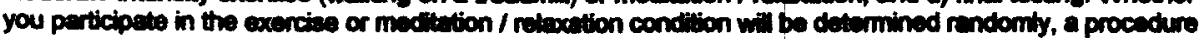
similar to thipping a coin'. The ecreening procedure conaists of completing two brief questionnires to eveluate your cerdiovesculer and poycholocical risk thens in terms of either hourt disease or extreme anxiety / depreseion. In addition, if you have been diernoeed with and treeted for breast cancer, or if you are pregnent, mecical authorization will be necessery in order for you to perticipate in the study.

If you are of pro-menopeused age, your two-hour secsion may be schoculad on a day during the luted phase of the menstreal cycle (epproximetely 10 deys following cesestion of menstruetion). During baseline testing, your heert rate, blood preseure, hoight, wight, whist end hip cincumference will be meseured. Heert rate will be moasured using a sensor contained in a strep that fits eround your chest that tranalis a

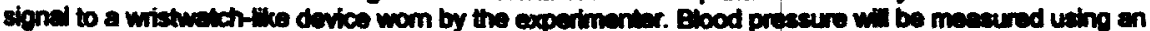
inflatable culf that fits around your upper arm. You will then be edked to complete a brief interview about

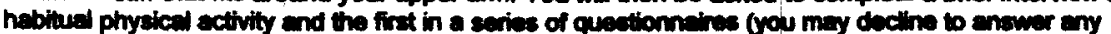

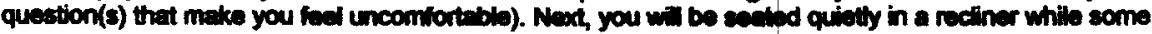
phyalological measures are made using sensors altuched to the surface of your foreheed (EMG, muscle tension) and fingers of one hend (putee, aweet otand activity and temperature). At the end of the bescline period, you will be akked to provide ratings of how you are beving, uling two spoint scales and a brief questionnaiv. Beseline teeting will be followed by either exurcies or meditution / relescation, the duration of Which will be between 2025 minutes.

FVMM STUDiEs COMmTTES

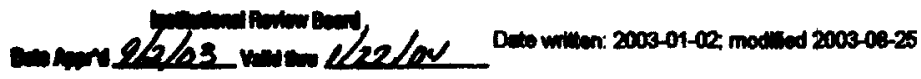


If you receive the exercise condition, your heent rete will be contimuousty monitored and you will periodically be asked to rate how you fed and your level of physical exertion. In the meditition / relaxation condition, your haert rata will be continuoushy monitored. In both conditions, physiological measures (musclo tenaion, aweat gland activity, temperature and pubs) wim be made continuousty.

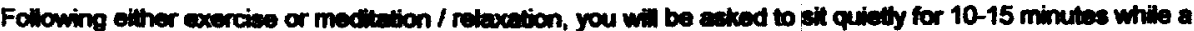
final set of phyeiologicel and quectionnaire moesures are then. At the end of this period, the physiological sensors will be removed prior to your leeving the leboratory. When the study has been completed, you will be sent an overall summary of the reauls (please note that incividuat reloults will not be made aveileble).

Potental Riaks

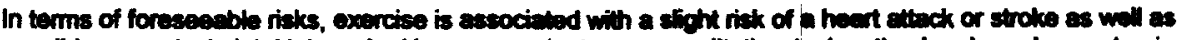

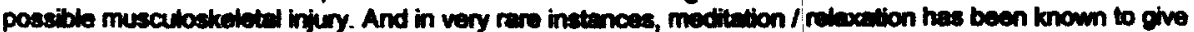
rise to foelings of panic-like anxiety. There may atso be risks that are currently unforeseen. If you are prognent and wish to perticiputo in this study, you should discuss the ritks of doing so with your physician before obtaining medical authorizetion (there mey be risks to you or to an embryo or fotus that ane currenthy unforeseen).

\section{Benentis}

The possible benefits of this study inchude laeming about a technique for manaing streas / aviety that you moy personally find beneficiel, es well as providing informetion leamed from this study that may be helphil to others. There is no poychological or medical necessity that you perticiperte in this study; non-participalton is a viable altemative.

\section{Research Rolatid hijury}

If you are injured (due to exerciae) as a reaut of your participation in this study, treedment for the injury will be provided at University Houpitel. You or your inteurence compeny will be billed for the costs of such medicel treetment. It is your responsibiiny to find out what costs your ineurence will cover. Additional compensation, for things such as lost wepes, inconvenience or discomfort, will not be provided. If you feel

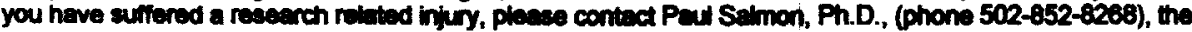

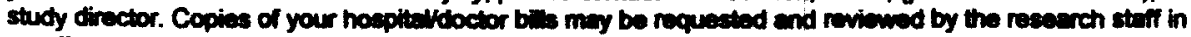
an effort to determine coets of care. These bills will be kept confidentid.

\section{Coeturcompenatetion}

You will not be peid for your perticipation in this study. There will be no costs to you for perticipating. However, you or your insurence compeny will be billed for all oflice visite end procedures that are pent of routine medical care to treat your diseese (thet wouls be dons regurdiess of whecher or not you were

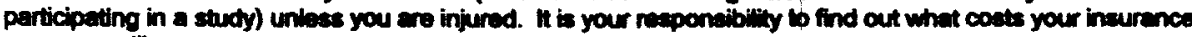
company will cover.

\section{Conficentiality}

Although abeolute confidentielity cannot be ounranteed, confidentiality will be protected to the extent permilted by lan. Should the dita collected from this study be published, your identity will not be revealed. The Human Studies Commitwe and the sponsoor may inspect your resenchermedicel records. The Investigator will supply your information to those responsible for regutelory and finencial overaight of research subjects. Those reaponsible for finencial oversight of research perticipents at this inatitution may review your reseanch records. This is necessary so that eny claim(s) for benefits arising from services rendered to you either as an inpelient or as an outpelient can be compliated and submittad property.

HPAA Ruscourch Axthotration

The Health Insurance and Portabity Act of 1896, eflective April 14, 2003, provides federe' sefopuards with regand to protected heelth information (PHI). PHI inctudes demographic informetion boout you, such as, your name, address, aco, and sax, as well as your modical hiatory, results of physical oxaminations and laboratory tests, medications titen and results of this Reseench Study. The use or disclosure of your PHI 
for research or by a third perty is not permitied unless it is athortad by you or meats one of the exceptions in the HIPMA regutetions. you will be asked as a condition of perticipetion in this Research Such to sign a HIPAA compliant "Research Authorization".

Voluntian Participation

Your perticipation in this reseerch study is voluntery. You may refues to pertictpete or withdraw your consent to paticlpete at any time without penally or losing benefit to which you are cthenwise entillod. Your decision to perticipats or not perticipate will not affect your medical treatment. Sirdificent new findings developed during the course of this study which may affect your wimingness to continus in the study will be provided to you.

Particlpation in Other Rasearch Stuthes

You moy not perticipete in this study if you are currently in another reseurch study:

\title{
Termination
}

The imestiontor reserves the right to borminete or end this study at any point or withdrew you from this study with or without your consent if hershe believes it is in your best interest.

\section{Resanch Subjetrs Richts and Contanct Persone}

You acknowedge that ell your present questions have been enswered in languege you cen understend and all future questions will be treeted in the seme munner. If you have amy quections bout the study, plecese contact one of the following individuals: Paul Seimon, Ph.D. (502-852-8288) or Kent Adams, Ph.D. (8528352).

If you heve any queations bout your riohts as a resecech abject, you may cell the Human Studies Committees office (502) 852-5188. You will be given the cpportunity to discuses any questions souk your rights as a research subject, in confidence, with a member of the commitbes. These ere independent committees composed of members of the Univereity community, staff of the inetitutions, as well es loy members of the community not connected with these institutions. The Conmites has reviewed this study.

You will be given a signed copy of this consent form to keep for your records.

Signature of Subjecthegel Representative

Signeture of Person Explaining the Consent Form

(ff other than the inveatigator)

Signature of Imvectigator

UST OF INVESTIGATORS

Poul Salmon, Ph.D.

Deperinent of Pachological and Brain Sciences

Kent Adems, Ph.D.

Depertment of Exercise Phyaiology

Sandra E. Sephton, Ph.D.

J. Grehem Brown Cencer Center

\section{Date Signed}

Dip Sipned

Date Signed

PHONE NUMBERS

502-852-8208

$502-852-8352$

502-852-1188

\section{HUMN STODIES COMMITIEES}

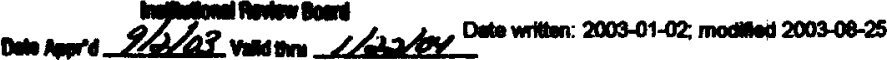




\section{CURRICULUM VITAE}

NAME: Paul Gregory Salmon

ADDRESS: Department of Psychological and Brain Sciences

University of Louisville

Louisville, Kentucky 40292

DOB: New York City, New York - March 13, 1948

EDUCATION \& TRAINING:

B.A., Psychology

University of Notre Dame, 1967-71

M.A., Clinical Psychology

DePaul University, 1971-74

Ph.D., Clinical Psychology

DePaul University, 1974-76

\section{PROFESSIONAL SOCIETIES:}

American College of Sports Medicine, Alliance of Health and Fitness Professionals National Register of Health Care Providers in Psychology

Society of Behavioral Medicine

\section{RECENT PUBLICATIONS:}

Dedert, E.A., Studts, J., Weissbecker, I., Salmon, P.G., Banis, P.L., and Sephton, S.E.:

Religiosity may Help Preserve the Cortisol Rhythm in Women with Stress-Related Illness. International Journal of Psychiatry in Medicine (In Press).

Sephton, S., Studts, J., Hoover, K., Weissbecker, I., Lynch, G., Ho, I., McGuffin, S., and Salmon, P.: Biological and psychological factors associated with memory function in fibromyalgia syndrome. Health Psychology 22(6), 592-597 (2003).

Weissbecker, I., Salmon, P., Studts, J. L., Floyd, A. R., Dedert, E. A., and Sephton, S. (2002) Mindfulness-based stress reduction and Sense of Coherence among women with fibromyalgia. 9(4), 297-307 Journal of Clinical Psychology in Medical Settings 
Salmon, P., and Swank, A. (2002) Exercise-based disease management guidelines for individuals with cancer: Potential applications in a high-risk mid-southern state. Journal of Exercise Physiology (online), 5(4), 1-10.

Adams, K., and Salmon, P. (2002) Acute training adjustments: Considering total stress. Strength and Conditioning Journal, 24(1) 63-64.

Wright, J., Wright, A., Salmon, P., et al (2002) Development and initial testing of a multimedia program for computer-assisted cognitive therapy. American Journal of Psychotherapy, 56(1), 76-86.

Salmon, P., Santorelli, S., and Kabat-Zinn, J. (1998) Intervention elements promoting adherence to mindfuless-based stress reduction programs in the clinical behavioral medicine setting. In S. A. Shumaker, E. Schron, J. Ockene and W. L. McBee (Eds.) Handbook for health behavior change, Second Edition. New York: Springer. Chapter 10, p. 239-266.

Salmon, P., and Meyer, R.G. (1998) Notes from the green room: Coping with stress and anxiety in musical performance. San Francisco: Jossey-Bass Publishers. (originally published by Lexington Press, Lexington, Massachusetts 1992).

\section{RECENT NATIONAL CONFERENCE ABSTRACTS \& POSTERS}

Sephton S.; Ross G.; Wellhausen S.; Studts J.; Ghate S.; Floyd A.; Banis P.; Salmon P. Psychoneuroimmune effects of stress and support in patients with lung cancer. Journal of Psychosomatic Research, August 2003, vol. 55, no. 2, pp. 170-170(1)

Dedert E.; Ghate S.; Floyd A.; Banis P.; Weissbecker I.; Hermann C.; Studts J.; Salmon P.; Sephton S. Spirituality effects symptom distress in patients with lung cancer. Journal of Psychosomatic Research, August 2003, vol. 55, no. 2, pp. 169-170(2)

Ghate S.; Whitten M.; Studts J.; Floyd A.; Banis P.; Weissbecker I.; Salmon P.; Sephton S. Emotional distress: adequacy of treatment for lung cancer patients. Journal of Psychosomatic Research, August 2003, vol. 55, no. 2, pp. 167-167(1)

Weissbecker I.; Dedert E.; Studts J.; Salmon P.; Sephton S. Traumatic events and health in women with fibromyalgia. Journal of Psychosomatic Research, August 2003, vol. 55, no. 2, pp. $165-165(1)$

Floyd A.; Ghate S.; Weissbecker I.; Banis P.; Studts J.; Salmon P.; Sephton S. Sense of coherence: relationships with distress, quality of life, and medication use in lung cancer patients. Journal of Psychosomatic Research, August 2003, vol. 55, no. 2, pp. 164-164(1)

Ulmer, C.S., Weissbecker, I., Sephton, S., Studts, J., Banis, P. L., McGuffin, S., Hoover, $\mathrm{K}$., and Salmon, P. Demographic factors do not predict participation, adherence, or 
outcome in a meditation-based Stress Reduction (MBSR) Program for women with fibromyalgia. Poster presentation, Society of Behavioral Medicine, April 2002

Salmon, P., Weissbecker, I., McGuffin, S., Banis, P. L., Studts, J., and Sephton, S. Overweight is associated with pain, physical inactivity and neuroendocrine dysregulation in women with fibromyalgia. Poster presentation, Society of Behavioral Medicine, April 2002

Salmon, P., Todd, R., Studts, J., Weissbecker, I., Sephton, S., and Stamford, B. Outcome and compliance analysis of a program to lower heart disease risk. Poster presentation, Society of Behavioral Medicine, April 2002.

Weissbecker, I., Floyd, A., McGuffin, S., Salmon, P., Banis, P., and Sephton, S. Repressive defensiveness is related to physiological symptoms in women with fibromyalgia. Poster presentation, Society of Behavioral Medicine, April 2002

McGuffin, S., Studts, J., Weissbecker, I, Hoover, K., Banis, P., Salmon, P., and Sephton, $\mathrm{S}$. Emotional neglect and perceived stress are associated with neuroendorcine dysfunction in women with fibromyalgia. Poster presentation, Society of Behavioral Medicine, April 2002

Dedert, E., Banis, P., Weissbecker, I., Studts, J., Salmon, P., McGuffin, S., Hoover, K., Ulmer, C., Segerstrom, S., Dhabhar, F., and Sephton, S. Spiritual expression is linked with endocrine and immune function among women with fibromyalgia. Poster presentation, Society of Behavioral Medicine, April 2002

Salmon, P. Mindfulness meditation in behavioral medicine: Conceptual model and outcome research. Paper, Society of Behavioral Medicine, March 2001

Sephton, S.E., Lynch, G., Ho, I., Weissbecker, I., Callahan, C., Banis, P., and Salmon, P. Effects of a meditation program on symptoms of illness, memory, and neuroendocrine responses in women with fibromyalgia. Citation Poster, American Psychosomatic Society, March 2001.

Sephton, S.E., Salmon, P., Weissbecker, I, Ho, I., Callanan, C., and Banis, P. Effects of a Meditation program on symptoms of illness and neuroendocrine responses in women with fibromyalgia. Paper, Society of Behavioral Medicine meeting, Seattle WA, March 2001.

Banis, P., Weissbecker, I., Salmon, P. Callanan, C., Ho, I., and Sephton, S. E. The effects of a mindfulness-based stress reduction program on spirituality in women with fibromyalgia. Poster, Society of Behavioral Medicine meeting, Seattle WA, March 2001 